\title{
PERFORMANCE OF APPETITIVE OR CONSUMMATORY COMPONENTS OF MALE SEXUAL BEHAVIOR IS MEDIATED BY DIFFERENT BRAIN AREAS: A 2-DEOXYGLUCOSE AUTORADIOGRAPHIC STUDY
}

\author{
C. R. DERMON, $* \dagger$ A. STAMATAKIS,* O. TLEMÇANI $\ddagger$ and J. BALTHAZART \\ *Department of Biology, University of Crete, Heraklion 714 09, Crete, Greece \\ $\ddagger$ Department of Biochemistry, Research Group in Behavioral Neuroendocrinology, University of Liege, Liege B-4020, Belgium
}

\begin{abstract}
The in vivo autoradiographic deoxyglucose method was used to identify the functional brain circuits that are involved in the performance of appetitive and consummatory components of male sexual behavior in Japanese quail (Coturnix japonica). Two groups of castrated, testosterone-treated male quail were trained during 12 sessions to associate the view of a female behind a window with the opportunity to interact freely and to copulate with her. They developed, as a consequence, a social proximity response (staying close and looking through the window providing a view of the female) that has been used in previous experiments to measure appetitive sexual behavior. A third control group (also castrated and treated with testosterone) was allowed to view the female but not to copulate with her and therefore did not develop this proximity response. $2-{ }^{14} \mathrm{C}$-deoxyglucose was then injected i.p. to these birds and they were allowed to either copulate freely with a female (consummatory sexual behavior group) or express the social proximity response (appetitive sexual behavior group). The control group was provided a view of the female but these birds, although they were exposed to the same stimuli as birds in the appetitive group, did not express the social proximity response because they had never learned the association with the opportunity to copulate. Birds were killed 45 min after the deoxyglucose injection and their brains were processed for autoradiography. Densitometric analyses of the autoradiograms revealed that the expression of appetitive or consummatory aspects of male sexual behavior was associated with significant increases by comparison with the control group in the deoxyglucose incorporation in the nucleus mesencephalicus lateralis, pars dorsalis and in the nucleus leminsci lateralis. In addition, an increase in the deoxyglucose incorporation was specifically observed in the paleostriatum primitivum, rostral preoptic area, nucleus intercollicularis, nucleus interpeduncularis and third nerve but a decrease was observed in the dorsomedial part of the hippocampus and in the nucleus nervi oculomotori in birds of the consummatory sexual behavior group by comparison with controls. By contrast, in the appetitive sexual behavior group, significant increases in deoxyglucose incorporation were observed in two telencephalic areas, the intermediate hyperstriatum ventrale and neostriatum caudolaterale by comparison with the controls, but decreases were detected in the stratum griseum et fibrosum superficiale of optic tectum by comparison with the consummatory behavior group.

These studies demonstrate that the performance of appetitive or consummatory components of male sexual behavior affects in a specific manner the deoxyglucose uptake and accumulation in specific regions of the quail brain. Changes in metabolic activity were observed in steroid-sensitive areas, in auditory, visual and vocal brain regions, and in brain nuclei related to motor behavior but also in association telencephalic and limbic structures. These changes in oxidative metabolism overlap to some extent with metabolic changes as revealed by immunocytochemistry for the immediate early gene products Fos and Zenk, but many specific reactions are also detected indicating that these techniques are not necessarily redundant and, together, they can provide a more complete picture of the brain circuits that are implicated in the control and performance of complex behaviors. (C) 1999 IBRO. Published by Elsevier Science Ltd.
\end{abstract}

Key words: cerebral metabolic activity, reproductive behavior, forebrain areas, preoptic area, vocal control regions, basal ganglia.

Male reproductive behavior can be usefully divided into its appetitive and consummatory components. ${ }^{27}$ Appetitive sexual behavior is characterized by searching and approaching a potential mate, whereas the consummatory component of this behavior refers to the actual sexual contact resulting in copulation. In Japanese quail, appetitive sexual behavior (ASB) has been studied with the use of a variety of learning procedures developed by Domjan and his colleagues. ${ }^{45-47}$ This behavior is testosterone-dependent, as demonstrated by the fact that low levels of circulating testosterone induced by exposing males to short photoperiods $\mathrm{s}^{39,76,83}$ or by surgical castration prevent the acquisition of the learned social proximity response commonly used to quantify ASB. ${ }^{22,45}$ Moreover, males transferred from long days to short days will extinguish a previously acquired response. ${ }^{45}$ Consummatory

$†$ To whom correspondence should be addressed.

Abbreviations: ASB, appetitive sexual behavior; CCM, cloacal contact movements; CSB, consummatory sexual behavior; 2-DG, ${ }^{14} \mathrm{C}$-2-deoxyglucose; M, mount; MA, mount attempts; NG, neck-grab. sexual behavior (CSB) in quail consists of a sequence of stereotyped movements: neck grab, mount attempts, mounts and cloacal contact movements. The sex steroid hormone, testosterone is also required for the activation of this behavioral sequence. $^{2,4}$ A substantial amount of pharmacological, biochemical and cellular evidence has been accumulated that demonstrates that testosterone must first be metabolized into an estrogen by the enzyme aromatase to activate male copulatory behavior. ${ }^{13,14}$ More recent studies also show that the same enzymatic transformation is required for the activation of ASB. ${ }^{18}$

The neural sites of testosterone action on behavior have been recently the subject of intense research and attention has been particularly focussed on brain nuclei that contain the enzyme aromatase that is known to play a limiting role in behavioral activation. A combination of studies involving electrolytic lesions and stereotaxic implantation of testosterone or estrogens in the brain indicate that the medial preoptic nucleus, a sexually dimorphic nucleus of the preoptic area ${ }^{72}$ plays a key role in the activation of both ASB and CSB. ${ }^{16,17,23}$ 
Other brain areas also have to be implicated in the control of these two aspects of male sexual behavior but, to this date, they have not been fully identified.

One useful strategy for the identification of brain areas implicated in the control of specific behaviors consists in the study of the local brain activity in subjects expressing the behavior of interest. Several tools are potentially available to address this question. The analysis by in situ hybridization or immunocytochemistry of the expression of immediate early genes (e.g., $c$-fos and the corresponding protein Fos) has now been widely used in the context of sexual behavior. In mammals, the study of Fos induction suggests that olfactory/vomeronasal and genital/somatosensory stimuli associated with copulation and relayed by the medial amygdala and central tegmental field respectively activate a limbichypothalamic circuit that includes the preoptic area and bed nucleus striae terminalis. ${ }^{25,36,74,90,93}$ Interestingly, the homologous structures also express Fos in quail after copulation despite the facts that these birds are supposed to depend only marginally on olfactory stimuli during sexual interactions and that they are devoid of an intromittent organ so that somatosensory stimuli originating from the genital area should be quite different from what they are in mammals. ${ }^{66}$ In addition, Fos expression is observed in the hyperstriatum ventrale and nucleus intercollicularis (a vocal control area) of the quail brain after copulation, ${ }^{66}$ indicating that these regions also participate either in the activation of behavior or in the processing of stimuli encountered in these conditions. A similar pattern of brain activation has also been observed by the study of the immediate early gene, Zenk in copulating quail. ${ }^{11}$

An attractive alternative to the study of immediate early genes resides however in the analysis by autoradiography of the local 2-deoxyglucose incorporation. The in vivo ${ }^{14} \mathrm{C}-2-$ deoxyglucose (2-DG) autoradiographic method indeed provides a well established strategy for mapping functional polysynaptic events in the CNS. Neuronal activity is reflected in glucose utilization since function-related energy requirements are almost exclusively met from the oxidative catabolism of glucose supplied by brain blood flow. ${ }^{79}$ Specifically, the 2-DG method provides information on the rate of glucose phosphorylation in specific brain regions, which in turn is indicative of energy production. Dynamic alterations in glucose utilization reflect mainly energy requirements for electrical activity in nerve terminals (ion transport; $\mathrm{Na}^{+}$, $\mathrm{K}^{+}$-ATPase) of neuronal pathways rather than the biochemical processes taking place in the cell body. ${ }^{6,37}$ The contribution of neuronal terminals to overall glucose utilization is likely to be related to the greater surface area to volume ratios compared to perikarya. ${ }^{57}$ It must also be noted that increases or decreases in glucose use cannot be assigned to neuronal excitation or inhibition, because the energy requirements for synaptic inhibition are similar to those for synaptic excitation. ${ }^{1}$ The induction of immediate early genes is therefore indicative of a stimulation of transcription and protein synthesis in the perikarya while 2-DG is indicative of an increased oxidative metabolism mostly (but not exclusively) affected by the activity at the synapse level. There are situations where both co-occur but this needs not be the case.

In the present study, we used the in vivo 2 -DG autoradiographic method to identify areas of the quail brain that are activated during the expression of appetitive and consummatory aspects of male sexual behavior. This species appears to be exceptionally well-suited for such studies because previous work has shown that male quail exposed to high levels of circulating testosterone will, when presented to a sexually receptive female, spend a very large percentage of their time performing copulatory behavior. It has also been shown that a sexually mature male quail can spend as much as $75-90 \%$ of the day in front of a window providing visual access to a female with whom the male was previously allowed to copulate. ${ }^{46}$ This demonstrates the prominence of appetitive and consummatory aspects of sexual behavior in this species. Therefore, due to its high level of sexual activity, the Japanese quail appears to be an outstanding model for such studies. We identify here a number of brain areas that are significantly activated during the performance of these behaviors, as indicated by a change in local 2-DG incorporation and demonstrate that different brain areas are specifically activated by the performance of appetitive or consummatory aspects of male sexual behavior.

\section{EXPERIMENTAL PROCEDURES}

\section{Subjects and endocrine procedures}

Experiments were carried out on male Japanese quail (Coturnix japonica) that were purchased at the age of three to four weeks from a local breeder in Belgium (Dujardin farms, Liernu). Within one week of their arrival in the laboratory, all birds were castrated under total anesthesia (Hypnodil, Janssen Pharmaceutica, Beerse, Belgium, $15 \mathrm{mg} / \mathrm{kg}$ ) through a unilateral incision behind the last rib on the left side using procedures that were previously described. ${ }^{15,17}$ Two weeks later, all subjects received two 20-mm-long Silastic implants (Dow Corning no. $602-252 ; 1.57 \mathrm{~mm}$ i.d.; $2.41 \mathrm{~mm}$ o.d.) filled with crystalline testosterone and were left undisturbed for about two weeks when behavior testing was initiated. The cloacal gland of each subject was measured with callipers (greatest length $\times$ greatest width $=$ cloacal gland area) at regular intervals during the experiment in order to confirm the effectiveness of the testosterone treatment. This gland is an androgen-dependent structure ${ }^{75}$ and its size is highly correlated with plasma testosterone levels. ${ }^{38}$ Throughout their life at the breeding colony and in the laboratory, birds were maintained on a photoperiod simulating summer long days (16 light:8 dark). During the behavioral experiment, all birds were isolated in individual cages. Food and water were always available ad libitum. Food was however removed $8 \mathrm{~h}$ before the i.p. injection of 2-DG. All experimental procedures were in agreement with the Belgian laws on "Protection and Welfare of Animals" and on the "Protection of Experimental Animals" and the International Guiding Principles for Biomedical Research Involving Animals published by the Council for International Organizations of Medical Sciences. The protocols were approved by the Supervisor of Animal Care for the University of Liège.

\section{Behavioral procedures}

Screening for presence of copulatory behavior. Two weeks after the start of the treatment with testosterone, all subjects were first pretested for the occurrence of male typical copulatory behavior during four presentations to a sexually mature female. Presentations lasted $5 \mathrm{~min}$ each and took place in a small arena $\left(60 \times 40 \mathrm{~cm}^{2}\right)$. Subjects that displayed active copulatory behavior (presence of mount attempts and cloacal contact movements) during each test then entered the next phase of the experiment during which they learned the social proximity response used to measure appetitive sexual behavior. From that time on, subjects were randomly assigned to three different groups that were subjected to slightly different training procedures.

Test cage for learning of the social proximity response. The social proximity response was learned and tested in two-compartment test cages that were previously described in full detail. ${ }^{17,18,22}$ Briefly, each cage consists of a large compartment that houses the experimental male subject $\left(90 \times 90 \times 50 \mathrm{~cm}^{3}\right)$ and a smaller cage for stimulus females $\left(20 \times 26 \times 24 \mathrm{~cm}^{3}\right)$ that is centered on the left lateral wall of the main cage. The two compartments are separated by a vertically sliding door that can be remotely controlled by strings and pulleys. A 
small "window" (vertical slit, $1 \mathrm{~cm}$ [wide] $\times 15 \mathrm{~cm}$ [high]) is located in the middle of this door and provides the male with a limited visual access to the female. This window can be closed by an opaque swinging plywood panel attached by a hinge just above the door. The lower part of that panel is attached to a string and pulley system that allows for remote lifting of the panel. A square area of the floor $\left(30 \times 30 \mathrm{~cm}^{2}\right)$, located in the middle of the lateral left wall (in front of the door/ window) represents the test area for the bird's position. When the window is open, the male present in the main chamber can only see the female located in the lateral chamber if he stands in front of the window in the test area. This area is mounted on four springs and four microswitches (one in each corner) wired in parallel and powered by a $4.5 \mathrm{~V}$ battery so that depression of any of these switches generates a positive signal. The output signals are digitized and fed to a MacIntosh computer using commercially available hardware and software (MacADIOS 8ain A/D converter from GW Instruments, Somerville, MA). A specially designed program written in Basic records during the observations (5-min periods, see below) the total time spent by the bird in the test area and the number of times that the birds enters this area. Positions are sampled once every second.

Acquisition of the social proximity response. Appetitive sexual behavior in quail can easily and reliably be measured by a learned social proximity response. During this response, a male will stand continuously in front of a window providing a view of the female after he has been given an opportunity to copulate with her. ${ }^{22,46,48}$ This response is progressively acquired as males are repeatedly tested and allowed to copulate with the female. In the present experiment, each subject was tested 12 times on successive days (within a 19-days period) in order to fully acquire this response.

Each of these behavioral test lasted a total of $25 \mathrm{~min}$. The male was first introduced in the main chamber and the stimulus female was placed in the adjacent smaller cage. The "window" between the two compartments was closed at that time. Birds were given 5 min to habituate to the new environment. The position of the male was then continuously recorded during the next 5-min period with the window still closed. This provided a pre-experimental control record. The window was then opened and the position of the male was again recorded for $5 \mathrm{~min}$. During this period the number of times that the bird entered the test area in front of the window was recorded. The time spent by the experimental subject looking through the open window was also recorded during these $5 \mathrm{~min}$ (TIME). A beeper was activated and emitted a weak sound every $5 \mathrm{~s}$. At each beep, the observer recorded whether the subject was actually looking through the window or not (LOOK). Looking behavior was defined as a stereotyped positioning of the head that allows the subject to focus on the female through the window. This point sampling therefore furnished a score for the looking behavior ranging from zero (never observed) to 60 (behavior present at every beep). Data collected during this period provided a measure of the appetitive sexual behavior of the male. At the end of this period, the door separating the two compartments was lifted and the two birds were allowed to freely interact for $5 \mathrm{~min}$. During that time, the frequency and latency of the first occurrence of male sexual behaviors were directly recorded. The following behavior patterns were systematically noted: strut, neck-grab (NG), mount attempt (MA), mount (M) and cloacal contact movements (CCM) (See Refs 3 and 56 for a detailed description). These data provided a measure of the consummatory sexual behavior of the birds. The female was then removed from the experimental chamber where the male stayed for another $5 \mathrm{~min}$ before he was returned to his home cage.

Two groups of birds were tested each 12 times following this exact procedure. The third group of subjects was also tested in parallel, but for these birds, the door separating the large from the small compartment was never opened after the 5 min when the window was opened so that these subjects were never allowed to copulate with the female and as a consequence, they never learned the social proximity response.

\section{2-deoxyglucose experiments}

Based on behavioral results collected during the original screening for copulatory behavior and during the acquisition of the social proximity response, 12 subjects were chosen for the 2-DG incorporation study. A larger number of individuals was originally included in the study but only subjects that reliably displayed the intended behaviors were used in order to make sure that radioactive 2-DG would not be wasted in subjects that would then not perform the expected behaviors. Behavioral and morphological data presented in this paper only refer to those 12 individuals that were finally studied for 2-DG incorporation.

At the end of these learning trials, all birds were tested once in slightly modified behavioral procedures immediately after each subject had received an intraperitoneal injection of 2-DG at a dose of $100 \mu \mathrm{Ci} /$ $\mathrm{kg}$ in $200 \mu \mathrm{l}$ sterile saline, as previously described ${ }^{41,42,62,82}$ (New England Nuclear NEC-495). Birds were then 13-weeks-old.

In one group of four subjects (ASB group) that had acquired the social proximity response (door had been opened after the window), the subject was placed in the large compartment of the two-compartment cage immediately after the i.p. injection of 2-DG. A female was already located in the small compartment. The window separating the two parts was then immediately opened but the door stayed closed. The subjects were left in this situation for 40 min during which the experimenter continuously recorded the time spent by the male in the test area and the frequency of looks through the window. Cumulative scores for these two measures were collected for every successive 5 -min period in order to obtain information on the changes of behavior in time.

In the second group of four subjects that had acquired the social proximity response (CSB group), the male was similarly placed in the large chamber of the testing cage immediately after the injection of 2DG but in this case, the door and window separating the two compartments were immediately opened so that the male had free access to the sexually mature female. Consummatory reproductive behaviors (MA and $\mathrm{CCM}$ ) were then continuously recorded for $40 \mathrm{~min}$ (in periods of 5 min as above).

Finally, in the third group of control (Ctrl) subjects that had never acquired the social proximity response (the door between the two compartments had never been opened and males had never had access to the female in that cage although they had copulated during the four tests in the small arena), the male was placed in the large compartment of the testing cage immediately after the 2-DG injection. A female was placed in the small compartment and the window between the two compartments was immediately opened (but the door remained closed). The time spent by the male in the test area and the frequency of looks through the window were also observed for 40 min with subtotals being recorded every $5 \mathrm{~min}$. These birds provided behavioral controls for the manipulations and exposure to non-specific stimuli ("control" group). They were indeed exposed to the same environment including physical and social stimuli as the subjects in the ASB group but because they had not acquired the social proximity response, they payed little attention to the female.

Three birds belonging to each of the three experimental groups were always tested simultaneously in three similar adjacent cages. Animals were killed by decapitation $45 \mathrm{~min}$ after the $2-\mathrm{DG}$ injection. The brain was immediately dissected out of the skull, frozen on dry ice, and stored at $-75^{\circ} \mathrm{C}$ until sectioned for autoradiographic experiments.

Autoradiography and data analysis. All brains were cut in the coronal plane with a cryostat at $-20^{\circ} \mathrm{C}$ in $20-\mu \mathrm{m}$-thick sections. Sections were thaw-mounted on coverslips, rapidly dried on a hot plate and exposed to Amersham ${ }^{14} \mathrm{C}$-sensitive autoradiographic Hyperfilm $\beta$ max along with a set of plastic autoradiographic standards $\left({ }^{14} \mathrm{C}\right.$ Amersham), as previously described ${ }^{41,42,62} \mathrm{~A}$ set of two sections were collected every $80 \mu \mathrm{m}$. Adjacent sections were placed on microscope slides and counterstained with Cresyl Violet. Following three weeks of exposure, the films were developed and analysed with a MacIntosh based image analysis system (NIH Image, v. 1.61, Wayne Rasband, NIH, Bethesda, MD). Local metabolic activity (2-DG incorporation) was measured in 94 discrete brain structures separately in left and right side of the brain. Each structure was outlined and measured in four to six consecutive sections depending on its anteroposterior extent, using as reference the corresponding Nissl-stained section. Mean metabolic activity (as calibrated with standards, expressed in $\mathrm{nCi} / \mathrm{g}$ tissue) in each structure of each subject, was normalized by a factor $F$, to minimize individual subject differences. Whole brain mean 2-DG incorporation was estimated by measuring all sections in each animal divided by the number of sections. The F-factor was determined as the ratio of the average 2-DG incorporation of the whole brain of all animals analysed $(n=12)$ divided by individual animal's whole brain mean 2-DG incorporation.

For each brain structure considered, data were originally analysed by a two-way mixed design ANOVA with the three experimental groups (control, appetitive and consummatory sexual behavior) 

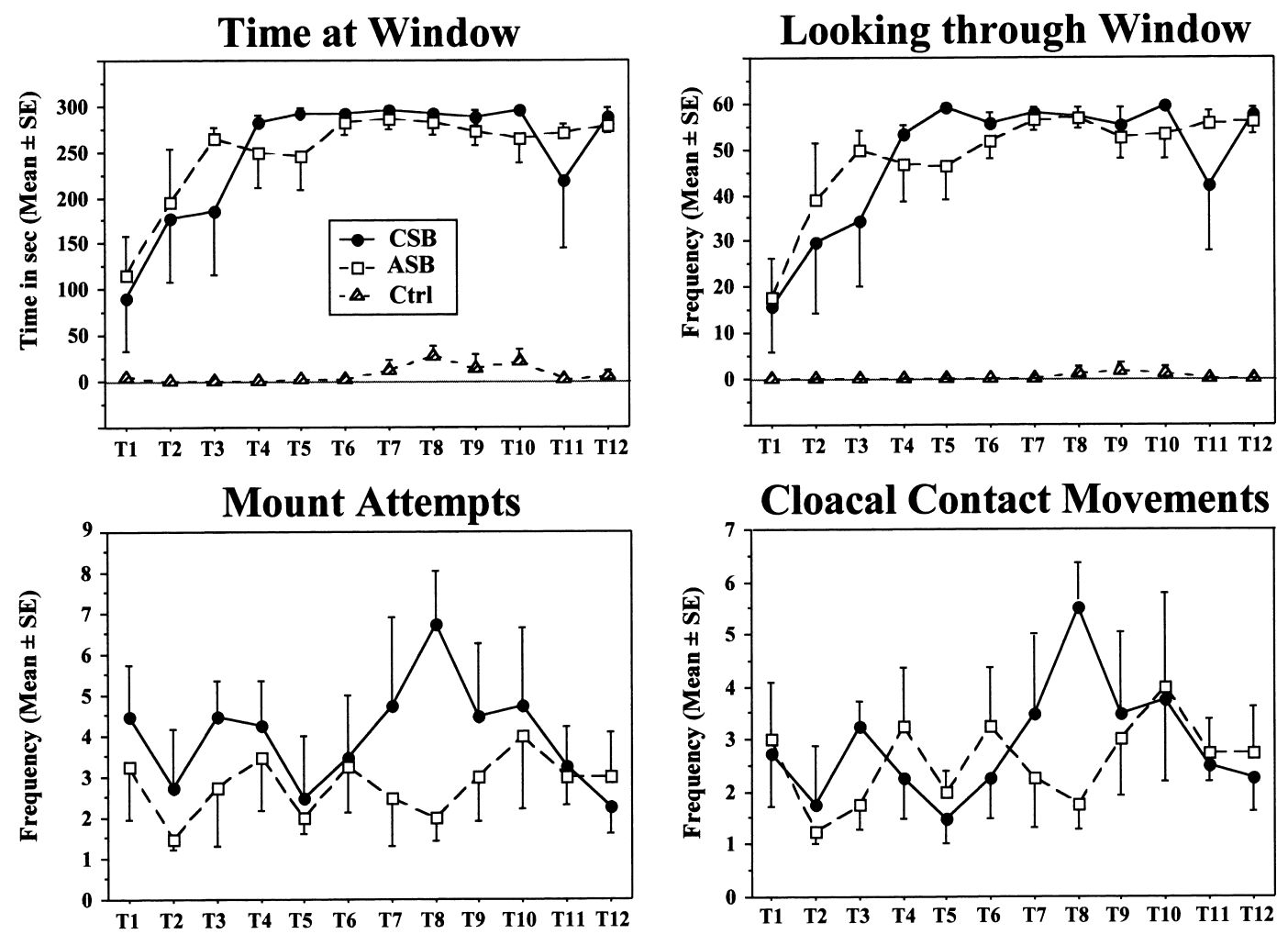

Fig. 1. Acquisition of the learned social proximity response and expression of male consummatory sexual behavior during the 12 training tests (T1 to T12) administered to the three groups of experimental birds. The groups to be used later for the study of CSB and ASB were repeatedly exposed to the view of the female paired with the opportunity to copulate and they rapidly acquired the proximity response as revealed by the time spent in front of and frequency of looks through the window. These birds also regularly expressed the CSB, mount attempts and cloacal contact movements. The control group (Ctrl) was repeatedly exposed to the view of the female but never allowed to copulate with her. Subjects in this group did not acquire the proximity response.

representing the independent factor and the two brain sides (left and right) representing the repeated factor. Because these analyses strongly suggested that brain metabolism is not or only very slightly lateralized (see corresponding result section), left and right values for each subject and brain area were then averaged and the resulting data were reanalyzed by one-way ANOVAs with the three experimental groups as an independent factor. When appropriate, post hoc testing was carried out to compare the three groups using the Tukey test, that provides an optimal compromise between the risks of type I and type II errors.

Nomenclature used in this paper is based on the atlas of the chicken $^{64}$ or quail ${ }^{26}$ brain with minor modifications for the preoptic area and anterior hypothalamus as described in Panzica et al. ${ }^{71}$

\section{RESULTS}

\section{Behavioral data}

The two groups of subjects that had free access to the female during the 12 training tests (ASB and CSB) regularly displayed the consummatory sexual behaviors MA and CCM (Fig. 1). The other aspects of consummatory behavior (NG and $\mathrm{M}$ ) were obviously also observed but because these behaviors normally occur in sequence, the results obtained are redundant and therefore are not presented here.

No CSB was observed in birds of the third group (Ctrl) because they were never allowed free access to the stimulus female. These birds, like all others, had however been castrated and treated with testosterone and they were sexually competent as demonstrated by the fact that they had copulated during the four screening tests performed in a smaller test arena.

All subjects in the ASB and CSB group also rapidly developed the learned social proximity response indicative of appetitive sexual behavior. After four to five tests, this response had been fully acquired and all subjects were spending $80-90 \%$ of their time in front of the window providing visual access to the female. They were also looking very often through that window (frequency scores above 50 out of a possible maximum of 60). As expected based on previous work, ${ }^{18,22}$ these behaviors (TIME and LOOK) were essentially not observed in birds of the Ctrl group that were visually exposed to the female but not allowed to copulate with her.

After birds in the ASB and CSB groups had acquired the learned social proximity response, they were then allowed to express this response (ASB group) or to perform copulatory behavior (CSB group) during $40 \mathrm{~min}$ immediately after having been injected with radioactive 2 -DG. The control birds were placed in the same experimental conditions as birds in the ASB group to serve as controls for non specific effects of environmental stimulations and manipulations.

As could have been predicted based on the results of the last training sessions, all birds in the ASB group spent most of their time in front of and looking through the window providing visual access to the stimulus female. This behavior indicative of appetitive sexual behavior was maintained for the full duration of the 40 min test. In contrast, it was only rarely displayed in birds of the control group that were placed in the same experimental situation but had never learned the social proximity response (Fig. 2).

Birds in the CSB group who were placed immediately in contact with the stimulus female after being injected with 2-DG interacted sexually with these females throughout the 


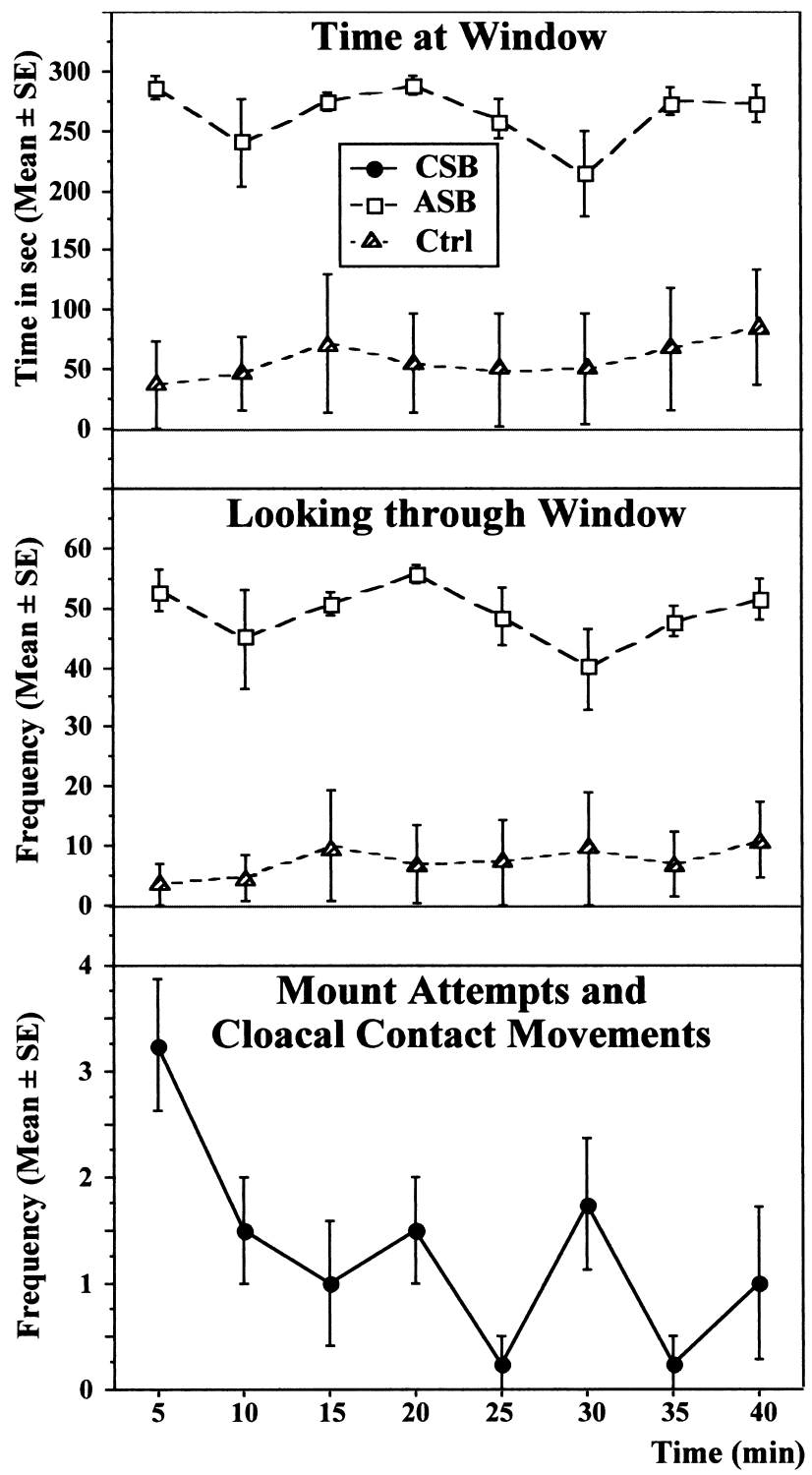

Fig. 2. Graphs illustrating the performance of appetitive and consummatory aspects of male sexual behavior in the three experimental groups (as defined in Fig. 1) during the $40 \mathrm{~min}$ behavior test carried out immediately after the injection of 2-DG. Birds in the ASB but not in the Ctrl group consistently expressed high levels of appetitive sexual behavior as revealed by the time spent in front of and frequency of looks through the window. Consummatory sexual behaviors were expressed with high frequencies in the CSB group.

40 min. The frequency of MA and CCM was highest during the first 5 min of interactions but after an initial decline in frequency, these behaviors were regularly observed for the rest of the observation period.

\section{Regional metabolic activity in male quail brain}

The metabolic activity (expressed in $\mathrm{nCi} / \mathrm{g}$ tissue) in the brain of quail tested in the conditions described above was highly heterogeneous (Fig. 3).

The highest rate of glucose uptake was detected in the ectostriatum, a primary visual area of the forebrain (Fig. $3 \mathrm{~A}-\mathrm{B})$. A very high activity $(>450 \mathrm{nCi} / \mathrm{g})$ was observed in the intermediate and lateral neostriatum, and paleostriatum augmentatum, in five thalamic nuclei: nucleus rotundus, ovoidalis, pretectalis, subpretectalis and spiriformis lateralis, in the nucleus mesencephalicus lateralis Pars dorsalis, in the substantia nigra centered on the nucleus tegmenti pedunculopontinus pars compacta and in the fasciculus prosencephali lateralis. The quail field $\mathrm{L}$ also had high metabolic activity as previously reported in the pigeon. ${ }^{92} \mathrm{~A}$ moderate activity (300-450 nCi $/ \mathrm{g}$ ) characterized the hyperstriatal areas, neostriatum, paleostriatum primitivum, lobus parolfactorius, archistriatum, nucleus taeniae, the thalamic nuclei geniculatus lateralis Pars ventralis, dorsolateralis anterior, and dorsomedialis anterior, the nucleus ruber, optic tectum, isthmic and pontine nuclei, the granular and to a smaller degree the molecular layer of the cerebellum and the nucleus cerebellaris internus. The bulbus olfactorius, area corticoidea lateralis, hippocampus, cortex piriformis, septum, hypothalamic nuclei, preoptic area, nucleus intercollicularis, nucleus interpeduncularis, locus coeruleus, and the white matter exhibited lower metabolic activities (Tables 1-4, Fig. 3).

\section{Lateralization of ${ }^{14} \mathrm{C}$-2-deoxyglucose incorporation}

Results of the two-way mixed ANOVA (experimental groups and side of the brain as independent and repeated factors, respectively) identified only a small number of structures where a lateralization of metabolic activity could potentially exist. Significant main effects of the repeated factor (brain side) were only observed in the nucleus rotundus, nucleus anterior medialis hypothalami in its medial and caudal part, and nucleus pretectalis as well as in two telencephalic regions, the neostriatum lateral and cortex piriformis. All these differences were significant at the level $P<0.05$ but had a very small amplitude. In each of these cases, the metabolic activity was higher in the left side than right side. In addition, interactions between the two factors in the ANOVA (experimental groups and side) were significant for the ansa lenticularis and nucleus dorsomedialis anterior thalami.

This small number of differences (six out of 94) that were observed almost corresponds to what would be expected by chance given the large number of regions that were compared. These results provide no conclusive evidence for a marked functional lateralization, and if lateralization occurs, it has a small amplitude and concerns brain areas where no experimental effect was detected (see below). Therefore, the effects of behavior on 2-DG incorporation that are presented below exclusively refer to the means of left and right side values.

Effects of performance of appetitive and consummatory sexual behavior on brain ${ }^{14} \mathrm{C}-2$-deoxyglucose incorporation

Performance of sexual behaviors resulted in complex differences between groups (both higher and lower 2-DG incorporations by comparison with controls) in the metabolic activity of motor, sensory and integrating functional circuits of male quail brain. These effects are summarized in Tables 1-4. Statistically significant changes were observed $(P<0.05$ in the ANOVA) in the telencephalic areas intermediate hyperstriatum ventrale, neostriatum caudolaterale, paleostriatum primitivum, hippocampus medial part, and tuberculum olfactorium (Table 1). Interestingly, the post hoc Tukey compromise test indicated that the telencephalic areas intermediate hyperstriatum ventrale and neostriatum caudolaterale increased their metabolic activity selectively in the ASB group, while in the CSB group a highly significant 
CONTROL APPETITIVE BEHAVIOR BEHAVIOR
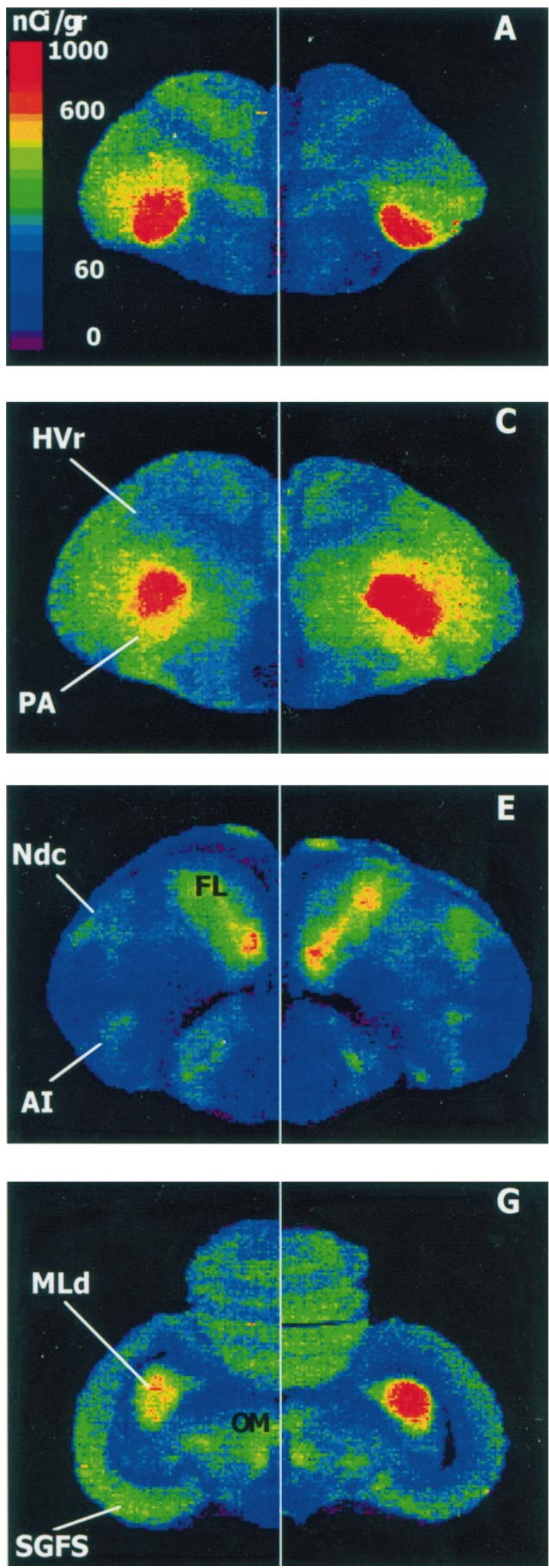

CONTROL CONSUMMATORY BEHAVIOR BEHAVIOR
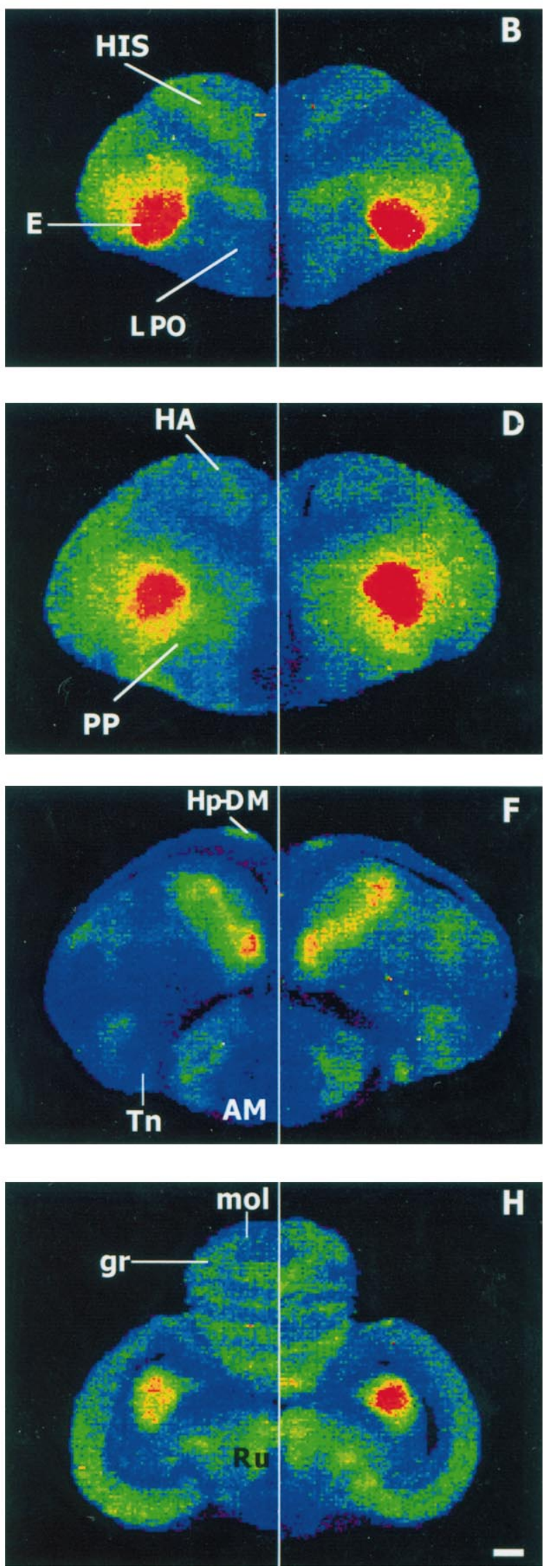
Table 1. Effects of appetitive and consummatory behavior on 2-deoxyglucose incorporation" in Japanese quail telencephalon

\begin{tabular}{|c|c|c|c|c|c|}
\hline \multirow[b]{2}{*}{ Brain region } & \multicolumn{3}{|c|}{ Behavioral performance } & \multirow[b]{2}{*}{$F$-value } & \multirow[b]{2}{*}{$P$-value } \\
\hline & $\mathrm{CSB}$ & ASB & Control & & \\
\hline \multicolumn{6}{|l|}{ Dorsal ventricular ridge } \\
\hline Hyperstriatum accessorium & $402 \pm 19$ & $373 \pm 8$ & $438 \pm 29$ & 2.36 & \\
\hline Intermediate hyperstriatum ventrale & $358 \pm 20$ & $405 \pm 10^{*}$ & $336 \pm 8$ & 6.49 & 0.018 \\
\hline Hyperstriatum ventrale rostral & $399 \pm 5$ & $434 \pm 9$ & $439 \pm 22$ & 2.45 & \\
\hline Hyperstriatum dorsale & $379 \pm 7$ & $383 \pm 13$ & $421 \pm 28$ & 1.57 & \\
\hline Hyperstriatum intercalatum supremum & $450 \pm 20$ & $514 \pm 18$ & $493 \pm 35$ & 1.63 & \\
\hline Neostriatum frontale & $516 \pm 8$ & $574 \pm 33$ & $511 \pm 19$ & 2.46 & \\
\hline Neostriatum intermedium frontal & $416 \pm 16$ & $485 \pm 28$ & $445 \pm 28$ & 2.00 & \\
\hline Neostriatum intermedium & $467 \pm 17$ & $443 \pm 20$ & $484 \pm 35$ & 0.66 & \\
\hline Neostriatum lateral & $602 \pm 23$ & $574 \pm 11$ & $571 \pm 30$ & 0.56 & \\
\hline Neostriatum & $462 \pm 9$ & $440 \pm 23$ & $444 \pm 8$ & 0.61 & \\
\hline Neostriatum caudolaterale & $405 \pm 4$ & $441 \pm 22^{*}$ & $370 \pm 9$ & 6.58 & 0.0174 \\
\hline Field L & $582 \pm 5$ & $587 \pm 37$ & $556 \pm 28$ & 0.39 & \\
\hline Ectostriatum & $922 \pm 21$ & $889 \pm 33$ & $852 \pm 28$ & 1.59 & \\
\hline Nucleus basalis & $375 \pm 20$ & $383 \pm 31$ & $364 \pm 19$ & 0.14 & \\
\hline Bulbus olfactorius & $277 \pm 16$ & $251 \pm 32$ & $268 \pm 4$ & 0.40 & \\
\hline Tractus fronto-archistriaticus & $307 \pm 17$ & $283 \pm 13$ & $325 \pm 14$ & 2.05 & \\
\hline Fasciculus prosencephali lateralis & $485 \pm 30$ & $470 \pm 6$ & $484 \pm 17$ & 0.17 & \\
\hline Tractus quintofrontalis & $322 \pm 13$ & $320 \pm 19$ & $316 \pm 13$ & 0.05 & \\
\hline \multicolumn{6}{|l|}{ Paleostriatal complex } \\
\hline Paleostriatum augmentatum & $527 \pm 9$ & $536 \pm 29$ & $479 \pm 12$ & 2.63 & \\
\hline Paleostriatum augmentatum rostral & $528 \pm 30$ & $538 \pm 13$ & $584 \pm 31$ & 1.30 & \\
\hline Paleostriatum primitivum & $405 \pm 11^{*}$ & $343 \pm 12^{+}$ & $358 \pm 7$ & 11.00 & 0.0038 \\
\hline Lobus parolfactorius & $391 \pm 14$ & $427 \pm 25$ & $398 \pm 43$ & 0.39 & \\
\hline \multicolumn{6}{|l|}{ Archistriatal complex } \\
\hline Archistriatum intermedium & $370 \pm 11$ & $363 \pm 9$ & $370 \pm 12$ & 0.13 & \\
\hline Nucleus taeniae & $394 \pm 17$ & $397 \pm 27$ & $403 \pm 31$ & 0.03 & \\
\hline \multicolumn{6}{|l|}{ Limbic pallium } \\
\hline Area parahippocampalis & $312 \pm 18$ & $336 \pm 36$ & $332 \pm 15$ & 0.26 & \\
\hline Hippocampus & $281 \pm 15$ & $290 \pm 22$ & $298 \pm 16$ & 0.25 & \\
\hline Hippocampus medial part & $373 \pm 19 *$ & $466 \pm 14^{+}$ & $450 \pm 13$ & 10.65 & 0.0042 \\
\hline Area corticoidea lateralis & $284 \pm 15$ & $323 \pm 7$ & $281 \pm 16$ & 3.39 & \\
\hline Cortex piriformis & $273 \pm 9$ & $255 \pm 13$ & $282 \pm 12$ & 1.42 & \\
\hline Tuberculum olfactorium & $392 \pm 7$ & $381 \pm 45$ & $488 \pm 27$ & 4.81 & 0.0426 \\
\hline Nucleus septalis lateralis & $226 \pm 2$ & $226 \pm 8$ & $224 \pm 10$ & 0.02 & \\
\hline Nucleus septalis medialis & $268 \pm 14$ & $263 \pm 10$ & $257 \pm 15$ & 0.17 & \\
\hline Tractus septomesencephalicus & $285 \pm 19$ & $267 \pm 11$ & $276 \pm 9$ & 0.50 & \\
\hline
\end{tabular}

\#Values represent the mean \pm S.E.M. of 2-DG uptake expressed in nCi/g tissue. Analysis by one-way ANOVA ( $F$ and $P$-values shown) followed by Tukey's compromise post hoc test showed statistical difference.

*compared with control group; ${ }^{+}$compared with CSB group.

metabolic increase in a part of the basal ganglia, the paleostriatum primitivum was observed (Fig. 3D). A decrease in metabolic activity was detected in the hippocampus medial part in the CSB group (Fig. 3F) and in tuberculum olfactorium in both the ASB and CSB groups (Fig. 4IA-B), but the later effect was not significant by the post hoc test.

Somewhat surprisingly, in the diencephalon, the anterior part of the preoptic area was the only region whose metabolic activity was significantly affected by the experimental treatments. Tukey tests revealed that the 2-DG incorporation increased in this area specifically in the CSB group but no change was observed in the group performing the appetitive response (Table 2, Fig. 4IA-B).

In contrast, at the level of mesencephalon and rhombencephalon, the metabolic activity was affected in a large number of brain regions $(P<0.05$ in the ANOVA) in the ASB and/or
CSB groups (Tables 3 and 4). The Tukey tests indicated that performance of CSB induced a significant decrease of the metabolic activity in the nucleus nervi oculomotori, but increased the metabolic activity in the nucleus mesencephalicus lateralis pars dorsalis (Fig. 3H), nucleus intercollicularis (Fig. 3H), nucleus interpeduncularis (Fig. 4IC-D), and nucleus lemnisci lateralis (Fig. 4IE-F). Metabolic activity was increased in the ASB group in two nuclei that were also activated in the CSB group, namely the nucleus mesencephalicus lateralis pars dorsalis (Fig. 3G) and nucleus lemnisci lateralis. Moreover, the superficial layers of the optic tectum showed statistically significant changes in activity, but the post hoc Tukey tests failed to indicate significant differences with the control group. The 2-DG accumulation in the ASB group was however significantly lower than in the CSB group (Table 3, Fig. 3G-H).

Fig. 3. Color-coded autoradiograms illustrating the neuroanatomical distribution of 2-DG incorporation in coronal sections of quail brain and the localized changes in birds of the ASB (A, C, E, G) or CSB (B, D, F, H) groups by comparison with control birds. AI archistriatum intermedium, AM nucleus anterior medialis hypothalmi, E ectostriatum, FL Field L, gr cerebellar granular layer, HA hyperstriatum accessorium, HIS hyperstriatum intercalatum supremum, Hp-DM hippocampus medial part, HVr hyperstiatum ventrale rostral, LPO lobus parolfactorius, MLd nucleus mesencephalicus lateralis pars dorsalis, mol cerebellar molecular layer, Ndc neostriatum caudolaterale, OM nucleus nervi oculomotori, PA paleostiatum augmentatum, PP paleostriatum primitivum, Ru nucleus ruber, SGFS stratum griseum et fibrosum superficiale, Tn nucleus taeniae. Scale bar $=1 \mathrm{~mm}$. 
Table 2. Effects of appetitive and consummatory behavior on 2-deoxyglucose incorporation" in Japanese quail diencephalon

\begin{tabular}{|c|c|c|c|c|c|}
\hline \multirow[b]{2}{*}{ Brain region } & \multicolumn{3}{|c|}{ Behavioral performance } & \multirow[b]{2}{*}{$F$-value } & \multirow[b]{2}{*}{$P$-value } \\
\hline & CSB & ASB & Control & & \\
\hline Preoptic area & $244 \pm 2^{*}$ & $222 \pm 8^{+}$ & $220 \pm 6$ & 4.91 & 0.0362 \\
\hline Nucleus preopticus medialis & $237 \pm 8$ & $243 \pm 10$ & $229 \pm 8$ & 0.62 & \\
\hline Commissura anterior & $227 \pm 15$ & $237 \pm 9$ & $217 \pm 3$ & 0.95 & \\
\hline Fasciculus prosencephali lateralis & $424 \pm 36$ & $409 \pm 17$ & $424 \pm 29$ & 0.10 & \\
\hline \multicolumn{6}{|l|}{ Thalamus } \\
\hline Nucleus dorsolateralis anterior thalami & $323 \pm 16$ & $349 \pm 13$ & $381 \pm 22$ & 2.79 & \\
\hline Nucleus dorsomedialis anterior thalami & $311 \pm 21$ & $320 \pm 23$ & $304 \pm 17$ & 0.15 & \\
\hline Nucleus habenularis lateralis & $247 \pm 21$ & $269 \pm 8$ & $252 \pm 10$ & 0.67 & \\
\hline Nucleus habenularis medialis & $296 \pm 18$ & $303 \pm 3$ & $289 \pm 16$ & 0.22 & \\
\hline Nucleus geniculatus lateralis pars ventralis & $361 \pm 19$ & $395 \pm 14$ & $391 \pm 19$ & 1.13 & \\
\hline Nucleus rotundus & $583 \pm 31$ & $533 \pm 5$ & $534 \pm 7$ & 2.42 & \\
\hline Nucleus intercalatus thalami & $340 \pm 17$ & $367 \pm 4$ & $357 \pm 19$ & 0.84 & \\
\hline Nucleus ovoidalis & $558 \pm 35$ & $581 \pm 11$ & $536 \pm 16$ & 0.96 & \\
\hline Nucleus pretectalis & $480 \pm 13$ & $494 \pm 22$ & $465 \pm 7$ & 0.89 & \\
\hline Nucleus subpretectalis & $473 \pm 27$ & $456 \pm 3$ & $458 \pm 15$ & 0.25 & \\
\hline Nucleus spiriformis lateralis & $485 \pm 15$ & $503 \pm 9$ & $493 \pm 20$ & 0.35 & \\
\hline Ansa lenticularis & $426 \pm 15$ & $405 \pm 7$ & $395 \pm 22$ & 0.86 & \\
\hline Stratum cellulare externum & $350 \pm 13$ & $399 \pm 34$ & $393 \pm 15$ & 1.35 & \\
\hline Substantia grisea centralis & $304 \pm 13$ & $310 \pm 16$ & $272 \pm 12$ & 2.26 & \\
\hline Fasciculus prosencephali lateralis & $382 \pm 25$ & $418 \pm 13$ & $396 \pm 6$ & 1.48 & \\
\hline Decussatio supraoptica & $243 \pm 14$ & $227 \pm 10$ & $250 \pm 20$ & 0.75 & \\
\hline Commissura posterior & $265 \pm 7$ & $292 \pm 9$ & $269 \pm 10$ & 2.88 & \\
\hline \multicolumn{6}{|l|}{ Hypothalamus } \\
\hline $\begin{array}{l}\text { Nucleus anterior medialis hypothalami, } \\
\text { rostral part }\end{array}$ & $238 \pm 8$ & $227 \pm 12$ & $239 \pm 12$ & 0.34 & \\
\hline $\begin{array}{l}\text { Nucleus anterior medialis hypothalami, } \\
\text { medial part }\end{array}$ & $245 \pm 15$ & $219 \pm 4$ & $242 \pm 9$ & 2.42 & \\
\hline $\begin{array}{l}\text { Nucleus anterior medialis hypothalami, } \\
\text { caudal part }\end{array}$ & $228 \pm 12$ & $216 \pm 11$ & $227 \pm 11$ & 0.32 & \\
\hline Nucleus paraventricularis magnocellularis & $247 \pm 9$ & $242 \pm 11$ & $235 \pm 16$ & 0.20 & \\
\hline Nucleus ventromedialis hypothalami & $233 \pm 8$ & $199 \pm 16$ & $211 \pm 9$ & 2.17 & \\
\hline Regio lateralis hypothalami & $249 \pm 14$ & $250 \pm 10$ & $259 \pm 14$ & 0.20 & \\
\hline Nucleus inferioris hypothalami & $222 \pm 17$ & $195 \pm 15$ & $210 \pm 11$ & 0.89 & \\
\hline Nucleus mammilaris medialis & $220 \pm 8$ & $197 \pm 23$ & $194 \pm 10$ & 0.93 & \\
\hline
\end{tabular}

\#Values represent the mean \pm S.E.M. of 2-DG uptake expressed in nCi/g tissue. Analysis by one-way ANOVA ( $F$ and $P$-values shown) followed by Tukey's compromise post hoc test showed statistical difference.

* compared with control group; ${ }^{+}$compared with CSB group.

Topographical analysis of cerebellar activity revealed significant changes in glucose consumption in the rostral part of molecular layer $(P<0.05$ in the ANOVA). These changes were apparently due to an increased activity in the ASB group but the Tukey compromise test failed to reveal a significant difference by comparison with the control group. Activity in the ASB group was however significantly higher than in the CSB group.

The white matter areas did not show significant metabolic changes as a function of the experimental treatments, with the exception of the nervus oculomotorius where glucose utilization was increased in the CSB group (Table 4; Fig. 4IC-D).

\section{DISCUSSION}

\section{Behavioral results}

In agreement with several studies from our and other laboratories, the two groups of birds (ASB and CSB groups) that were repeatedly exposed to the view of a sexually receptive female paired with the opportunity to copulate with her, readily learned the social proximity response that has been used previously to quantify appetitive sexual behavior in male quail. ${ }^{17,18,22,46-48}$ The control birds in which the view of the female was not paired with copulatory opportunity never developed this behavior. After approximately four training tests, the ASB and CSB birds were reliably expressing the learned response and were spending most of the test time in front of the window providing visual access to the female. The same results have been observed previously but the rapidity of acquisition of this response was slightly slower and the response was more variable. It must be noted however that data presented here concern four subjects in each group that were selected because they were displaying the expected behaviors very reliably. This was done to ensure that these subjects would perform the expected behaviors immediately after the injection of radioactive 2-DG so that they would provide useful results. The data described here therefore represent to some extent the best possible response that can be observed. They indicate that in these conditions, subjects will spend approximately $90 \%$ of their time watching the stimulus female after they have been trained through this procedure. This represents a very powerful response and very few aspects of appetitive sexual behavior in vertebrates actually occur with such a high degree of reliability to allow the type of metabolic study that was carried out here. Quail also reliably display copulatory behavior in laboratory situations and, as expected, they regularly performed cloacal contact movements during the $40 \mathrm{~min}$ of test after the injection of 2-DG. The intensity and frequency of occurrence of these two components of male sexual behavior make the quail 
Table 3. Effects of appetitive and consummatory behavior on 2-deoxyglucose incorporation ${ }^{\#}$ in Japanese quail mesencephalon

\begin{tabular}{|c|c|c|c|c|c|}
\hline \multirow[b]{2}{*}{ Brain region } & \multicolumn{3}{|c|}{ Behavioral performance } & \multirow[b]{2}{*}{$F$-value } & \multirow[b]{2}{*}{$P$-value } \\
\hline & CSB & ASB & Control & & \\
\hline Nucleus ruber & $397 \pm 16$ & $424 \pm 12$ & $461 \pm 21$ & 3.65 & \\
\hline \multicolumn{6}{|l|}{ Nucleus mesencephalicus } \\
\hline lateralis pars dorsalis & $632 \pm 10^{*}$ & $620 \pm 31 *$ & $535 \pm 13$ & 7.06 & 0.0143 \\
\hline Nucleus intercollicularis & $280 \pm 6^{*}$ & $239 \pm 15^{+}$ & $219 \pm 8$ & 9.21 & 0.0067 \\
\hline Nucleus opticus basalis & $314 \pm 5$ & $292 \pm 15$ & $338 \pm 16$ & 3.27 & \\
\hline Nucleus nervi oculomotori & $380 \pm 11^{*}$ & $418 \pm 8$ & $429 \pm 14$ & 5.25 & 0.0309 \\
\hline \multicolumn{6}{|l|}{ Nucleus tegmenti } \\
\hline pedunculo-pontinus, pars compacta & $470 \pm 9$ & $459 \pm 33$ & $465 \pm 11$ & 0.07 & \multirow{4}{*}{0.0085} \\
\hline Nucleus interpeduncularis & $295 \pm 11 *$ & $234 \pm 15^{+}$ & $227 \pm 12$ & 8.50 & \\
\hline Nucleus isthmi pars magnocellularis & $274 \pm 6$ & $269 \pm 10$ & $289 \pm 26$ & 0.39 & \\
\hline Nucleus isthmi pars parvocellularis & $377 \pm 19$ & $344 \pm 19$ & $384 \pm 30$ & 0.81 & \\
\hline Nervus oculomotorius & $186 \pm 4^{*}$ & $153 \pm 3^{+}$ & $149 \pm 5$ & 23.25 & 0.0005 \\
\hline \multicolumn{6}{|l|}{ Optic tectum } \\
\hline Stratum griseum et fibrosum superficiale & $393 \pm 8$ & $350 \pm 13^{+}$ & $383 \pm 10$ & 4.62 & \multirow[t]{4}{*}{0.0415} \\
\hline Stratum griseum centrale & $364 \pm 11$ & $336 \pm 6$ & $358 \pm 12$ & 2.13 & \\
\hline Stratum album centrale & $235 \pm 9$ & $204 \pm 4$ & $217 \pm 10$ & 3.67 & \\
\hline Tractus opticus & $164 \pm 8$ & $152 \pm 4$ & $157 \pm 6$ & 0.83 & \\
\hline
\end{tabular}

\#Values represent the mean \pm S.E.M. of 2-DG uptake expressed in nCi/g tissue. Analysis by one-way ANOVA ( $F$ and $P$-values shown) followed by Tukey's compromise post hoc test showed statistical difference.

*compared with control group; ${ }^{+}$compared with CSB group.

Table 4. Effects of appetitive and consummatory behaviour on 2-deoxyglucose incorporation\# in Japanese quail rhombencephalon

\begin{tabular}{|c|c|c|c|c|c|}
\hline \multicolumn{6}{|c|}{ Behavioral performance } \\
\hline Brain region & CSB & ASB & Control & $F$-value & $P$-value \\
\hline Nucleus nervi trochlearis & $366 \pm 13$ & $395 \pm 23$ & $378 \pm 16$ & 0.67 & \\
\hline Nucleus isthmo-opticus & $324 \pm 5$ & $346 \pm 10$ & $333 \pm 33$ & 0.32 & \\
\hline Nucleus semilunaris & $366 \pm 12$ & $340 \pm 15$ & $343 \pm 10$ & 1.25 & \\
\hline Locus coeruleus & $316 \pm 10$ & $290 \pm 13$ & $289 \pm 12$ & 1.70 & \\
\hline Nucleus subcoeruleus & $325 \pm 9$ & $294 \pm 15$ & $310 \pm 11$ & 1.64 & \\
\hline Nucleus papillioformis & $311 \pm 18$ & $305 \pm 11$ & $304 \pm 18$ & 0.06 & \\
\hline Nucleus lemnisci lateralis & $406 \pm 7 *$ & $408 \pm 15^{*}$ & $349 \pm 14$ & 6.83 & 0.0157 \\
\hline Nucleus reticularis pontis caudalis & $315 \pm 7$ & $327 \pm 9$ & $358 \pm 18$ & 3.36 & \\
\hline Nucleus pontis lateralis & $423 \pm 21$ & $311 \pm 32(+)$ & $390 \pm 30$ & 4.23 & 0.0506 \\
\hline Nucleus pontis medialis & $313 \pm 18$ & $300 \pm 27$ & $369 \pm 28$ & 2.15 & \\
\hline \multicolumn{6}{|l|}{ Cerebellum } \\
\hline Molecular layer, rostral part & $304 \pm 14$ & $367 \pm 13^{+}$ & $336 \pm 18$ & 4.29 & 0.0491 \\
\hline Molecular layer, medial part & $331 \pm 6$ & $355 \pm 15$ & $322 \pm 27$ & 0.85 & \\
\hline Molecular layer, caudal part & $308 \pm 3$ & $351 \pm 19$ & $315 \pm 22$ & 1.89 & \\
\hline Granular layer, rostral part & $406 \pm 13$ & $479 \pm 19$ & $437 \pm 37$ & 2.10 & \\
\hline Granular layer, medial part & $438 \pm 12$ & $455 \pm 22$ & $410 \pm 28$ & 1.11 & \\
\hline Granular layer, caudal part & $441 \pm 16$ & $483 \pm 8$ & $440 \pm 36$ & 1.25 & \\
\hline Nucleus cerebellaris internus & $581 \pm 13$ & $548 \pm 35$ & $490 \pm 30$ & 2.78 & \\
\hline
\end{tabular}

\#Values represent the mean \pm S.E.M. of 2-DG uptake expressed in nCi/g tissue. Analysis by one-way ANOVA ( $F$ and $P$-values shown) followed by Tukey's compromise post hoc test showed statistical difference.

*compared with control group; ${ }^{+}$compared with CSB group. Symbols in parenthesis indicate Tukeys's compromise tests that were significant but the associated ANOVA was not significant.

an ideal model for the mapping of brain areas involved in sexual behavior based on measures of local activity as done here with the 2-DG autoradiographic method or previously during immunocytochemical analyses of the expression of immediate early genes. ${ }^{11,66}$ Interestingly, the highest frequencies of copulatory behaviors were observed at the beginning of the 40-min test period that is immediately after the 2-DG injection (Fig. 2). This temporal distribution represents an additional advantage for the studies presented here because it is well known that the 2-DG incorporation in a specific brain area mostly reflects the activity of this area during the first $15 \mathrm{~min}$ after the injection. Copulatory behavior therefore had a maximal impact on the local utilization of glucose.

\section{Sex behavior and ${ }^{14} \mathrm{C}$-2-deoxyglucose incorporation}

The 2-DG in vivo autoradiographic method as applied here provided detailed anatomical evidence on the brain loci where changes in metabolic activity are specifically associated with the performance of specific aspects of male reproductive behavior. The quantitative densitometric analysis of the 2DG accumulation in cells allowed us to determine the specific neuroanatomical localization of relative metabolic changes. It must be noted that the present experiments did not provide absolute values for local rates of glucose utilization. The determination of these values would require the knowledge of specific kinetic parameters that are available for only a few species of mammals. ${ }^{79}$ These parameters could be obtained in 
I

CONTROL BEHAVIOR

nCi/gr
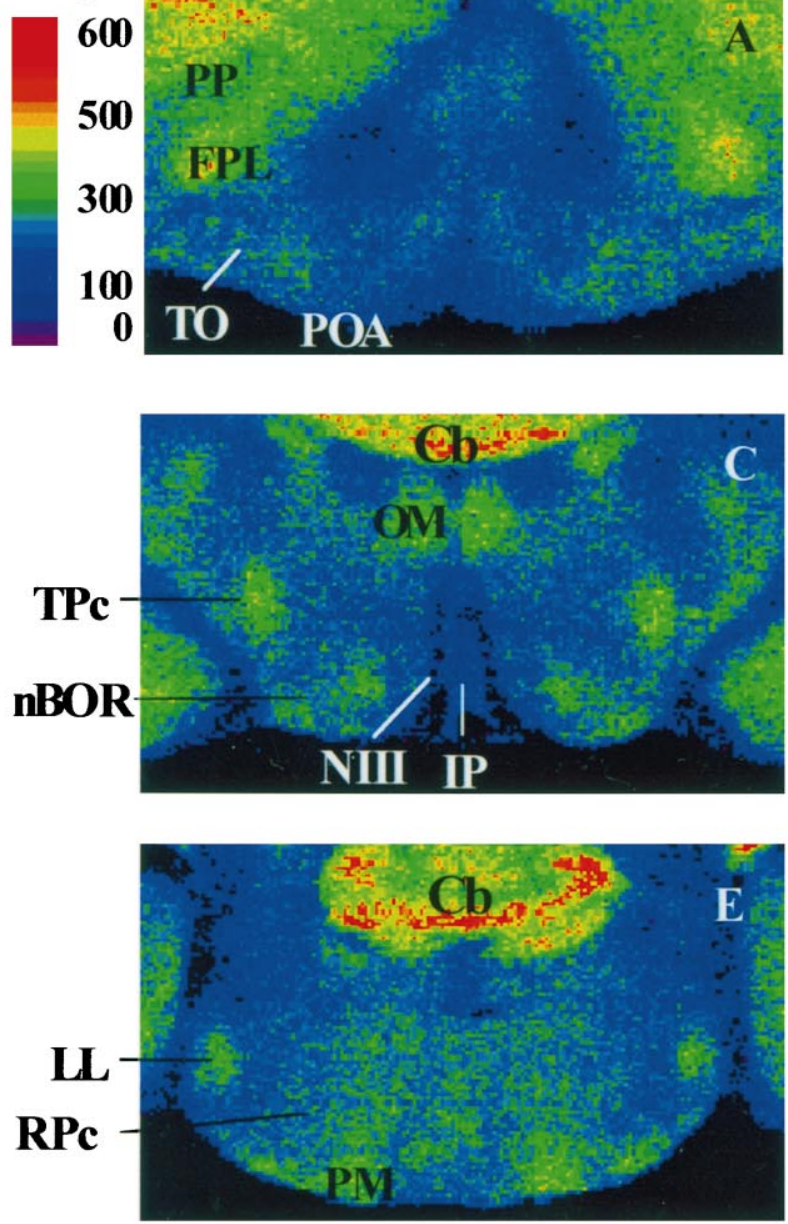

CONSUMMATORY BEHAVIOR
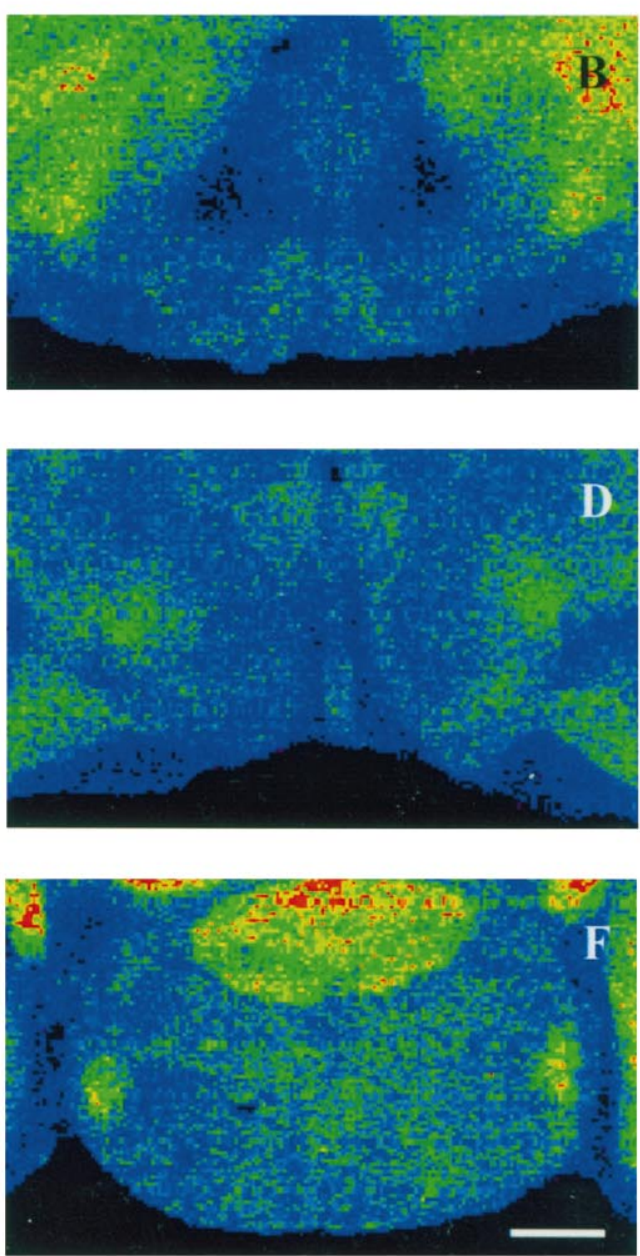

II

APPET ITIVE SEXUAL BEHAVIOR (ASB)

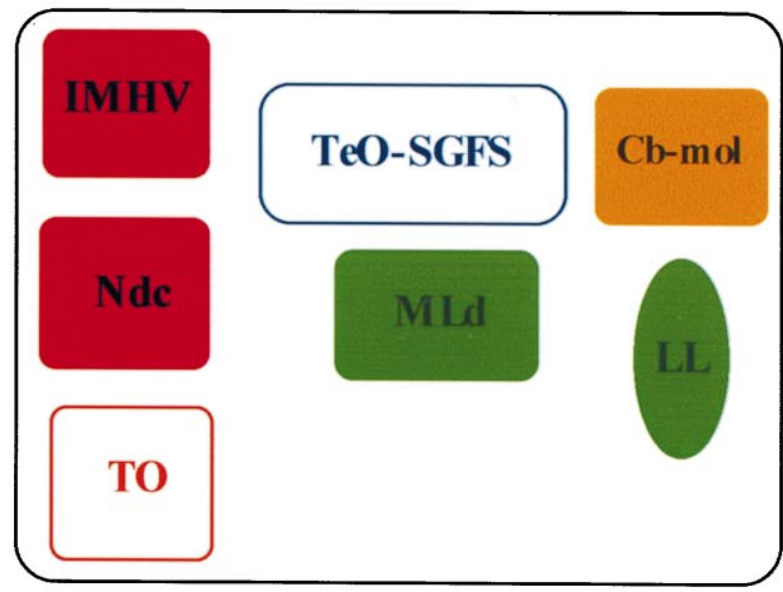

LIMBICINTEGRATING

VISU AL
CONSUMMATORY SEXUAL BEHAV OR (CSB)

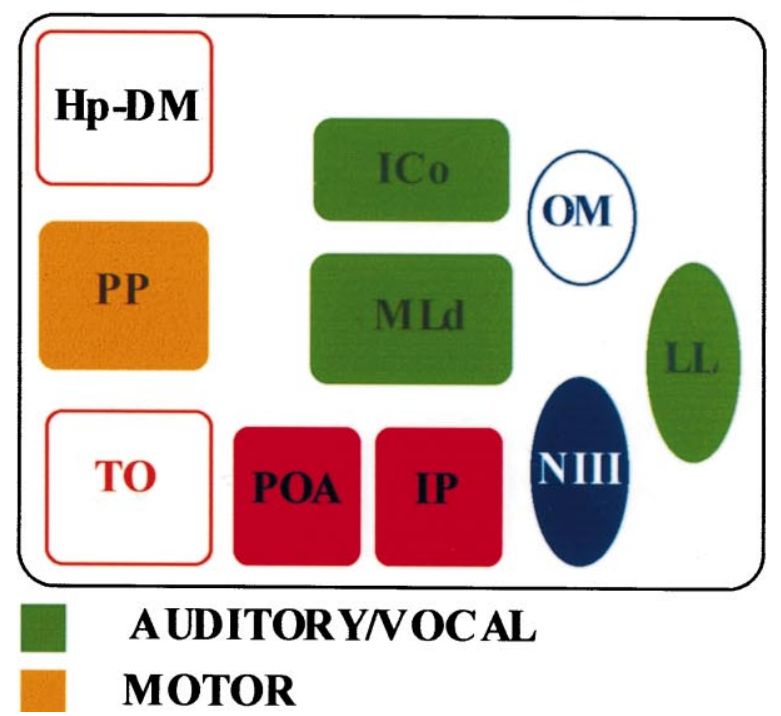


quail by serial measures of radioactivity in the blood but the repeated blood sampling that would be required to reach this goal would be difficult to perform in a relatively small bird and would obviously interfere with the performance of copulatory behavior. Therefore, only relative changes in incorporation could be assessed in the absence of knowledge of specific kinetic parameters for the 2-DG distribution in quail. Effort was also made to minimize animal suffering and reduce the number of animals studied per group. Therefore, small changes in glucose consumption may not be revealed by this relative quantification procedure, but on the other hand the detected differences are very robust and more likely to reflect major changes in the function of brain circuits.

The overall pattern of brain metabolic activity observed here in quail is similar to the pattern previously described for chick $^{62}$ and quail ${ }^{82}$ with the visual and auditory brain areas showing the highest levels of metabolic activity. The performance of appetitive or consummatory sexual behavior induced both increases and decreases of the metabolic activity in specific brain areas of the experimental groups by comparison with the control birds. These changes are summarized in Fig. 4II.

Briefly, three major types of changes were observed:

1. In a small number of nuclei, the performance of both appetitive and consummatory components of male sexual behavior induced similar alterations in the metabolic activity as identified by the 2-DG accumulation. These changes consisted in increases in activity in two nuclei implicated in auditory processing: the mesencephalic nucleus mesencephalicus lateralis pars dorsalis and the rhombencephalic nucleus lemnisci lateralis but decreases in metabolic activity in the telencephalic tuberculum olfactorium. These brain regions should therefore be part of the common neural circuits controlling both appetitive and consummatory aspects of male sexual behavior.

2. Numerous localized changes in metabolic activity were also specifically observed in the CSB group but were not present in birds that had only performed the appetitive part of the male sexual behavior. The majority of the cases consisted in increases of the metabolic activity. This was the case in steroid-sensitive areas such as the rostral preoptic area and nucleus intercollicularis, but also in many areas that are not known for being steroid-sensitive such as paleostriatum primitivum, nucleus interpeduncularis and nervus oculomotorius. A decrease in metabolic activity in the CSB group by comparison with controls was however observed in a few brain areas, namely the hippocampus medial part and nucleus nervi oculomotori.

3. Finally, the metabolic activity of a small number of brain areas was specifically affected in birds of the ASB group that had visual access to the female but could never copulate with her. These areas include two telencephalic areas (intermediate hyperstriatum ventrale and neostriatum caudolaterale), where increased activity was seen in both cases, as well as the retinorecipient layer of optic tectum stratum griseum et fibrosum superficiale, where decreased activity was observed.

The brain regions found to modify their metabolic activity during the performance of behavior are further analysed in systems functional pathways.

\section{Preoptic area}

Interactions with a sexually mature female were associated with a significant metabolic activation specifically in the rostral part of anterior preoptic area, at the level of the tractus septomesencephalicus. Similarly, an activation of the preoptic area as revealed by the induction of Fos-immunoreactive cells was observed following the expression of copulatory behavior in male quail. ${ }^{66}$ These studies provide converging evidence further supporting the involvement of this brain area in the integration of copulation, indicating that the preoptic area is essential for male mating behavior, as it is in mammalian species. ${ }^{67,85}$ Accordingly, it has been found in quail that lesions of the preoptic area severely disrupt the expression of male copulatory behavior. ${ }^{16,17,23}$ Furthermore, implants of testosterone in the preoptic area activate male-typical copulation in castrated male quail, ${ }^{16,23,89}$ suggesting that gonadal steroids activate the behavior through a direct action on this diencephalic area.

It must be observed, however, that the activation of the preoptic area as detected here by the 2-DG accumulation was anatomically limited to the most rostral part of this region while the activation indicated by the induction of the Fos protein extended throughout the rostrocaudal extent of the area $^{66}$ and the implants or lesions studies seem to indicate the more caudal nucleus preopticus medialis as the focus of steroid action in the activation of male sexual behavior. No definitive explanation is available at present for this apparent discrepancy but, as mentioned above, it must be recalled that the 2-DG incorporation essentially reflects metabolic activity at the synapse level while Fos induction is related to protein synthesis in the cellular perikarya. Therefore these two measures potentially provide converging evidence of activation in a given brain area but there is not necessarily a complete overlap between the regions that are highlighted by the two methods. It must also be observed that although no significant increase in 2-DG incorporation was detected in the more caudal nucleus preopticus medialis (the key area for steroid action on copulatory behavior ${ }^{72}$ ), a numerical increase was nevertheless observed both in the CSB and ASB groups by comparison with controls. It remains possible that these changes would turn out to be significant if larger numbers of subjects were studied. This would fit in well with recent results indicating that lesions of specific part of the nucleus preopticus medialis disrupt the expression of appetitive and/or consummatory components of male sexual behavior. ${ }^{17}$ However, as indicated above, the 2-DG method is particularly

Fig. 4. (I) Color-coded autoradiograms showing 2-DG incorporation in control birds (A, C, E) and birds of the CSB group (B, D, F) at the level of preoptic area $(\mathrm{A}, \mathrm{B})$, nucleus interpeduncularis (C, D) and lateral lemniscus (E, F). Cb cerebellum, FPL fasciculus prosencephali lateralis, IP nucleus interpeduncularis, $\mathbf{L L}$ nucleus lemnisci lateralis, nBOR nucleus opticus basalis, NIII nervous oculomotorius, OM nucleus nervi oculomotori, PM nucleus pontis medialis, POA preoptic area, PP paleostriatum primitivum, RPc nucleus reticularis pontis caudalis, TO tuberculum olfactorium, TPc nucleus tegmenti pedunculo-pontinus pars compacta. Scale bar $=1 \mathrm{~mm}$. (II) Summary of the changes in 2-DG incorporation observed in the brain of birds in the ASB and CSB groups that were allowed to perform the appetitive and consummatory aspects of male sexual behavior by comparison with control birds. Filled areas represent nuclei where an increase in 2-DG incorporation was observed, open areas correspond to regions where a decrease was detected. IMHV intermediate hyperstriatum ventrale,

TeO optic tectum, ICo nucleus intercollicularis (For additional abbreviations see Figs 3 and 4I). 
sensitive to changes in metabolic activity at the level of axon terminals while it is likely that the nucleus preopticus medialis contributes to the activation of sexual behavior (consummatory but also to some extent appetitive component) via steroid-induced changes in the perikarya of neurons located in this nucleus. These cellular effects are subsequently reflected in changes in a part of the numerous projection areas of the nucleus preopticus medialis. ${ }^{12,19,72}$ It is therefore quite possible that the involvement of the nucleus preopticus medialis in the activation of male sexual behavior does not imply the type of changes in neuronal activity that can be detected by the 2-DG autoradiographic method.

\section{Visual areas}

A selective significant metabolic depression characterized the retinorecipient stratum griseum et fibrosum superficiale during the performance of ASB, in which the main behavior exhibited was continuous watching through the window, behind which was the female quail. The optic tectum is a major visual area, at the basis of the tectofugal system projecting to nucleus rotundus, which in turn projects to ectostriatum. ${ }^{35}$ Tectal neurons respond to features that include location, movement, brightness and pattern and are known to play a key role in visual discrimination. However, electrophysiological studies suggest firing of tectal neurons in response to moving stimuli. ${ }^{52}$ In accordance, it is of great interest that, in the present study, the selective fixation of a fixed target was associated with a metabolic inhibition of the retinorecipient layers stratum griseum et fibrosum superficiale. Moreover, in addition to the major retinal input, the basal ganglia influences the tectal activity, via projections of two relay stations (nigra and spiriform lateralis) to the deep layers of the tectum, providing information on motor control systems ${ }^{60}$ that is integrated, within local tectal circuits, with visual and somatosensory information. It is therefore possible that the reduced metabolic activity observed in the tectum could be additionally related to the lack of motor and somatosensory activity, because the animals were not performing any motor program besides maintaining the fixed visual orientation. This evidence is in general agreement with the optic tectum function in orienting to visual stimuli by head movement and saccades.

\section{Auditory/vocal areas}

In birds, auditory stimuli are represented in the nucleus mesencephalicus lateralis pars dorsalis, the avian equivalent of the central nucleus of the mammalian inferior colliculus. Projections of the nucleus mesencephalicus lateralis pars dorsalis terminate in the ovoidalis complex, which in turn projects to the forebrain area, field L. ${ }^{59}$ Anatomical evidence suggests the existence of projections from the caudomedial part of paleostriatum primitivum to nucleus mesencephalicus lateralis pars dorsalis and nucleus intercollicularis, ${ }^{92}$ supporting the idea that there are relationships between the basal ganglia and auditory structures. Metabolic activation of nucleus mesencephalicus lateralis pars dorsalis was observed here following performance of both components of reproductive behavior. However, its ascending connections to thalamic and auditory forebrain did not show any detectable change in 2-DG incorporation. In contrast, the dorsal and ventral lateral lemniscal nuclei, that send ascending afferents to auditory thalamic nuclei and to nucleus mesencephalicus lateralis pars dorsalis ${ }^{91}$ were also found metabolically activated. The simultaneous activation of the nucleus lemnisci lateralis and of its projection area nucleus mesencephalicus lateralis pars dorsalis, suggests an excitatory nature of nucleus lemnisci lateralis projections to nucleus mesencephalicus lateralis pars dorsalis. It must be noted that a nearly significant metabolic activation of nucleus mesencephalicus lateralis pars dorsalis has been previously reported in male quail transferred from short days to long days, ${ }^{82}$ an experimental manipulation that increases the sexual arousal of subjects (although sexual behavior was impossible in this study because birds were individually caged).

The demonstration of a stimulation of the primary stations of the auditory pathway nucleus lemnisci lateralis-nucleus mesencephalicus lateralis pars dorsalis, in both birds engaging in anticipatory and consummatory sexual behavior, suggests that auditory information plays a major role in the performance of both components of sexual behavior in birds. However, no other relay station for auditory information, except for the area of neostriatum caudolaterale implicated in the processing of multiple sensory inputs (discussed below) was simultaneously activated. This therefore raises questions regarding the nature and specific functional significance of the activation detected in nucleus mesencephalicus lateralis pars dorsalis.

The mesencephalic nucleus intercollicularis, counterpart of mammalian pedunculopontine nucleus, that is known to play a major role in mediating vocal behavior in birds, also displayed a significant metabolic activation during the performance of copulatory behavior. It is known that the steroidsensitive nucleus intercollicularis includes many neurons that contain androgen and/or estrogen receptors, ${ }^{16,20,21,88}$ as well as high densities of receptors for neurotransmitters (adrenergic and cholinergic ${ }^{8-10}$ ) that are themselves modulated by steroids. $^{7}$ Testosterone implants at the level of nucleus intercollicularis activate crowing, an androgen-dependent maletypical vocalization. ${ }^{96}$ Electrical stimulation of nucleus intercollicularis also elicits a wide variety of natural calls and influences respiratory rate, ${ }^{5}$ and nucleus intercollicularis lesions reduce the occurrence frequency of crowing. ${ }^{77,78}$

The increased glucose utilization in nucleus intercollicularis was specific to the CSB group while birds performing appetitive behaviour only (ASB group) did not display a change in metabolic activity in this nucleus by comparison with control birds. Interestingly, a similar increase in activity in the nucleus intercollicularis following performance of copulatory behavior has previously been detected in immunocytochemical studies analysing the expression of the immediate early genes Fos and Zenk. ${ }^{11,66}$ Moreover, the transfer from short days to long days also tends to increase metabolic activity in nucleus intercollicularis, as detected by 2-DG autoradiography. ${ }^{82}$ The specific aspects of behavior that result in a metabolic change in nucleus intercollicularis have however not been precisely identified. It is indeed known that male quail decrease their crowing frequency when exposed to a female. If the metabolic changes observed in the nucleus intercollicularis of birds performing copulatory behavior relate to vocalization, one would then have to assume that the increased 2-DG incorporation reflects the activation of inhibitory circuits. In agreement with this interpretation it has been shown that the quail nucleus intercollicularis contains high densities of GABA receptors ${ }^{32,33}$ that 
could represent the neurochemical substrate for this behavioral inhibition (see Ref. 66 for discussion). Alternatively, it could be speculated that nucleus intercollicularis activation represents an indirect consequence of the activity increase in the preoptic area, given that projections from the preoptic area to nucleus intercollicularis have been previously reported. ${ }^{19}$ In addition, the mammalian equivalent of nucleus intercollicularis is known to be reciprocally connected with the substantia nigra. ${ }^{55}$ If such a connection also exists in birds, one might then speculate that the disinhibition of pallidal neurons during copulatory behavior (see basal ganglia discussion) results in tonic firing of nigral neurons, that is then reflected in the observed metabolic activation in nucleus intercollicularis. More studies (e.g., 2-DG studies in birds bearing lesions in nuclei that specifically project to the nucleus intercollicularis) would be needed to establish the significance of the changes in metabolic activity in this vocal nucleus.

\section{Basal ganglia and motor related areas}

Copulatory behavior is characterized by the performance of stereotyped movements that may explain why we detected a significant stimulation of the metabolic activity in the paleostriatum primitivum. The paleostriatum primitivum is suggested to be the counterpart of the mammalian globus pallidus. ${ }^{58,60,94}$ Anatomical studies have shown that its major input is represented by paleostriatum augmentatum dopaminergic axons that wrap completely the large paleostriatum primitivum neurons. The paleostriatum primitivum gives rise to most of the GABAergic sub-telencephalic projections of the paleostriatal complex (counterpart of mammalian pallido-tegmental system), via axons of the ansa lenticularis ${ }^{60}$ to nucleus dorsointermedius posterior thalami, nucleus spiriformis lateralis and substantia nigra. ${ }^{84}$ However, none of those well-documented projection areas showed any statistically significant metabolic changes, suggesting that metabolic stimulation of paleostriatum primitivum might reflect inhibition of the GABAergic cells in paleostriatum primitivum, ${ }^{44}$ which in turn does not affect metabolic activity in its projection areas. These findings are in agreement with studies in primates, that suggest that normal tonic activity of pallidal neurons inhibits their target neurons in the thalamus and mesencephalic tegmentum. The loss of this tonic inhibition by muscimol or kainic acid manipulation of the globus pallidus causes simultaneous contraction of the flexor and extensor arm muscles ${ }^{30,69}$ suggesting postural holding mechanisms. In addition, primate medial pallidal neurons decrease their firing in relation to movement ${ }^{54}$ and perhaps participate in reinforcing desired movements. Such withdrawal of the pallidal inhibition of thalamocortical pathways might be concerned not only with controlling the activity of the required agonist muscles, but also in facilitating synergistic muscle activity to increase stiffness and maintain posture. ${ }^{65}$ We propose a similar functional role of the basal ganglia (disinhibition of pallidal neurons) in the execution of the motor copulatory program in quail.

It is also of great interest to note that depression of activity in the cerebellum was observed in animals of the CSB but not the ASB group. Subjects in this latter group were characterized by a decrease or absence of locomotor activity because they were, during most of the test, immobilized in front of and looking through the window. Furthermore, the pontine nucleus pontis lateralis, which is considered as a source of mossy fiber inputs to the cerebellar cortex and is suggested to excite the granule cells, showed decreased activity in the ASB compared to the CSB group. Pontine nuclei receive inputs from the striatum, tectum, and spinal cord. It is therefore possible that the metabolic depression of nucleus pontis lateralis is due to the reduced activity of the tectal efferents in the nucleus, a hypothesis supported by the concurrent depression of activity observed the stratum griseum et fibrosum superficiale layer of the optic tectum in the ASB group.

\section{Somatosensory telencephalic and limbic areas}

Complex responses were observed in the limbic association areas. Copulatory behavior in the CSB group was associated with an inhibition of metabolic activity in the medial hippocampal area, whereas, appetitive sexual behavior was specifically characterized by stimulation of hyperstriatum ventrale and neostriatum caudolaterale. In addition, metabolic activity in the tuberculum olfactorium was significantly decreased in both behavioral conditions.

The region ventral to the paleostriatum primitivum and lobus parolfactorius including the tuberculum olfactorium has been considered as the visceral/limbic basal ganglia in birds. Tuberculum olfactorium contains a dense accumulation of GABAergic fibers and receives inputs from the olfactory bulb, lobus parolfactorius and lateral septum. ${ }^{84}$ One study also briefly reports tuberculum olfactorium projections to the septum, archistriatum, lateral corticoid area, cortex piriformis, area temporo-parieto-occipitalis, hippocampus, medial hyperstriatum ventrale including intermediate hyperstriatum ventrale, dorsomedial thalamic nucleus, entire habenular region and ventral hypothalamic area, ${ }^{81}$ but these connections are not fully characterized. The present study provides strong evidence for the participation of tuberculum olfactorium to functional circuits related to reproductive behavior, both in its anticipatory and consummatory phase. Whether tuberculum olfactorium inhibition is functionally related monosynaptically or polysynaptically to the other two areas simultaneously affected by CSB and ASB performance (nucleus mesencephalicus lateralis pars dorsalis and nucleus lemnisci lateralis) is not known at present. It must be noted however that increases in 2-DG accumulation were observed in nucleus mesencephalicus lateralis pars dorsalis and nucleus lemnisci lateralis while decreases were observed in tuberculum olfactorium; this may be related to the inhibitory, GABAergic nature of this latter brain area.

Recent studies suggest an involvement of the avian hippocampal system in spatial memory tasks. ${ }^{34,73}$ In addition, the avian hippocampal complex appears to be visceral/limbic in nature and based on the localized presence of multiple neurochemical markers it has been proposed to have four major subdivisions and to be homologous of the Ammon's horn and parahippocampal area of the dentate gyrus in mammals. ${ }^{49,50,63}$ The dorsomedial area of the avian hippocampus is rich in GABAergic fibers, that may primarily reflect intrinsic connections and includes the most intense labeling of serotoninergic, cholinergic and catecholaminergic fibers and neuropil of the ascending afferents of the medial fiber tract. ${ }^{63,84}$ This is the region where a significant reduction in glucose utilization was detected in this study, following copulatory behavior. The mechanism underlying this decreased activity in the CSB group is not well understood 
at present but it may represent a specific inhibition of the intrinsic circuits activity.

In addition, the mesencephalic nucleus interpeduncularis, that was found to be metabolically activated in the CSB group, sends projections to the hippocampal formation. ${ }^{86,95}$ The reversed relationship of metabolic changes in nucleus interpeduncularis and hippocampus medial part could imply a possible disinhibition mechanism, supported by the dense GABAergic fibers found in nucleus interpeduncularis. ${ }^{84}$ Moreover, nucleus interpeduncularis is known to receive descending cholinergic projections via the fasciculus retroflexus from the medial habenula, which in turn receives input from olfactory areas and regions related to the limbic system. The anatomical connections and the functional involvement of nucleus interpeduncularis in sexual behavior supports the idea that nucleus interpeduncularis in the tegmentum integrates incoming sensory/olfactory information with appropriate motor responses.

The present study also demonstrated that, among the two forebrain somatosensory systems described in birds, only the caudal multimodal representation area, that contains large receptive fields not somatopically organized, ${ }^{53}$ seems to be affected by reproductive behaviors. This area could be divided functionally into an input region in the caudal neostriatum intermediate and the adjacent neostriatum caudale and a secondary region in the hyperstriatum ventrale. ${ }^{53}$ The integrative functions of hyperstriatum ventrale are supported by connections to sensory and motor (archistriatum and paleostriatum) telencephalic areas. Hyperstriatum ventrale receives projections from neostriatum intermediate/neostriatum caudale and is therefore considered as a secondary area, in contrast to neostriatum caudale that receives only thalamic input and is a primary sensory area. Specific increases in glucose uptake were localized in the intermediate hyperstriatum ventrale, known to be a key area for aversive learning in chicks, ${ }^{62,80}$ and for visual imprinting. ${ }^{31}$ The present findings are in agreement with a previous report demonstrating the induction of the immediate early gene Zenk in cells localized in the HV of birds performing the same behavior task, i.e. the learned social proximity response indicative of appetitive sexual behavior. ${ }^{11}$ An increased Fos expression has also been detected in the same brain area in birds that had performed copulatory behavior in the exact same conditions. ${ }^{66}$ Moreover, intermediate hyperstriatum ventrale receives direct input from the neostriatum caudolaterale complex, ${ }^{68}$ which is a major target of the belt regions of the visual ectostriatum and of the L1 and L3 auditory field L. ${ }^{92}$ Neurons in the intermediate hyperstriatum ventrale have been demonstrated to respond to visual stimuli and are closely associated with learning responses after visual imprinting. ${ }^{29,31}$ The increases in glucose uptake observed during the appetitive behavior in both neostriatum caudolaterale and intermediate hyperstriatum ventrale support the notion that their functional connections are excitatory. They also confirm the integration role of intermediate hyperstriatum ventrale in visually-related experience.

The avian neostriatum caudolaterale area includes several functional units although it appears cytoarchitectonically homogeneous. Biochemical, histochemical, immunocytochemical, hodological and behavioral studies suggest that the complex area of neostriatum caudolaterale is comparable to the prefrontal cortex of mammals. ${ }^{43,87}$ The neostriatum caudolaterale is characterized by a high dopamine to noradrenaline ratio and is densely innervated by dopaminergic fibers, originating from the mesencephalic tegmentum, ${ }^{43,87}$ which is similar to the mesocortico-prefrontal system in mammals. It is considered an area involved in the control of delayed alternation learning. ${ }^{70}$ In addition to the intra-telencephalic tertiary sensory afferents, the neostriatum caudolaterale complex is innervated by the polysensory nucleus dorsolateralis posterior thalami that is known to include bi or tri-modal neurons integrating visual, somatosensory and auditory information. ${ }^{61}$ Recent 2 -fluoro-deoxyglucose experiments have revealed that the same sub-area in the dorsocaudal neostriatum, as identified in the present study, is activated in acoustically and visually imprinted chicks, suggesting that it is involved in the processing of learned visual information. ${ }^{28}$ This sub-area was termed the neostriatum caudolaterale, and it constitutes a major relay for visual information via afferents from ectostriatal belt. ${ }^{68}$ This tertiary multimodal integration is characteristic of the mammalian prefrontal cortex known to mediate complex cognitive operations possibly related to its thalamic afferents. ${ }^{24,40}$ The present knowledge is however still not sufficient to firmly establish an homology between these areas in mammals and birds. The present study suggests that, in addition to other association functions, neostriatum caudolaterale is involved in circuits integrating sensory information in relation to emotional events, like the anticipation of reward.

\section{CONCLUSIONS}

The present study demonstrates that the regional cerebral 2DG uptake and accumulation is affected in a specific manner in birds that were allowed to express the appetitive or consummatory components of male sexual behavior. Changes in metabolic activity were observed in steroid-sensitive areas (preoptic area, nucleus intercollicularis), in auditory and vocal brain regions (nucleus mesencephalicus lateralis pars dorsalis, nucleus lemnisci lateralis, nucleus intercollicularis), and in brain nuclei related to motor behavior (paleostriatum primitivum, nucleus pontis lateralis, cerebellum) but also in sensory and limbic structures (tuberculum olfactorium, intermediate hyperstriatum ventrale, neostriatum caudolaterale, hippocampus medial part, nucleus interpeduncularis). Interestingly, however, the changes did not concern the entire functional pathways for auditory and visual systems, but modifications were observed in the primary sensory areas. Possible secondary changes of metabolic activity in target relay stations, were not detected, probably because they were compensated by the activity of other functional connections unrelated to sexual behavior. However, the limbic areas, that are multimodal integration areas, were mainly affected by sexual performance and particularly by the appetitive response to the view of a female. A similar finding was reported in a recent study in mammals. ${ }^{51}$

The changes in oxidative metabolism as indicated here by 2 -DG autoradiography overlap to some extent with metabolic changes as revealed by immunocytochemistry for the immediate early gene products Fos and Zenk, but many specific reactions are also detected indicating that the activation of protein synthesis in neuronal perikarya is not necessarily correlated at the anatomical level with the activation/inhibition of synaptic activity. It is therefore quite enlightening to analyse changes in brain activity by 
both technical approaches that can provide in some cases converging evidence for the implication of a given brain area in the control of a specific behavior but can also point to a dissociation of metabolic/functional events. Taken together, these techniques provide a more complete picture of the brain circuits that are implicated in the control and performance of complex behavior such as male sexual behavior.
Acknowledgements - This work was supported in part by grants from the NIMH (R01 MH50388), the Belgian FRFC ( $n$ 9.4565.96F), and the University of Liège (Fonds Spéciaux pour la Recherche) to JB, and Greek GSRT of Ministry of Development, PENED 95 (grant $n$ 1610) to $\mathrm{CD}$. The collaboration between CD and JB was also supported by a grant from the European Union Human Capital and Mobility Program (grant no. CHRX-CT-94-0472). Lindsy Bielby analysed part of the autoradiograms, while she was an Erasmus exchange student in Crete University.

\section{REFERENCES}

1. Ackermann R. F., Finch D. M., Babb T. L. and Engel J. Jr (1984) Increased glucose metabolism during long-duration recurrent inhibition of hippocampal pyrammidal cells. J. Neurosci. 4, 251-264.

2. Adkins E. K. (1975) Hormonal basis of sexual differentiation in the Japanese quail. J. comp. Physiol. Psychol. 89, 61-71.

3. Adkins E. K. and Adler N. T. (1972) Hormonal control of behavior in the Japanese quail. J. comp. Physiol. Psychol. 81, 27-36.

4. Adkins E. K. and Pniewski E. E. (1978) Control of reproductive behavior by sex steroids in male quail. J. comp. Physiol. Psychol. 92, 1169-1178.

5. Armitage S. E. and Seller T. J. (1981) Midbrain regions involved in call production of Japanese quail. Experientia 37, 847-848.

6. Astrup J., Sorensen P. M. and Sorensen H. R. (1981) Oxygen and glucose consumption related to $\mathrm{Na}^{+}-\mathrm{K}^{+}$transport in canine brain. Stroke 12, 726-730.

7. Ball G. F. and Balthazart J. (1990) Steroid modulation of muscarinic cholinergic and $\alpha_{2}$-adrenergic receptor density in the nucleus intercollicularis of the Japanese quail. Eur. J. Neurosci. 2, 828-835.

8. Ball G. F., Foidart A. and Balthazart J. (1989) A dorsomedial subdivision within the nucleus intercollicularis identified in the Japanese quail (Coturnix coturnix japonica) by means of $\alpha_{2}$-adrenergic receptor autoradiography and estrogen receptor immunohistochemistry. Cell Tiss. Res. 257, $123-128$.

9. Ball G. F., Nock B., McEwen B. S. and Balthazart J. (1989) Distribution of $\alpha_{2}$-adrenergic receptors in the brain of the Japanese quail as determined by quantitative autoradiography: implications for the control of sexually dimorphic reproductive processes. Brain Res. 491, 68-79.

10. Ball G. F., Nock B., Wingfield J. C., McEwen B. S. and Balthazart J. (1990) Muscarinic cholinergic receptors in the songbird and quail brain: a quantitative autoradiographic study. J. comp. Neurol. 298, 431-442.

11. Ball G. F., Tlemçani O. and Balthazart J. (1997) Induction of the Zenk protein after sexual interactions in male Japanese quail. NeuroReport 8, 2965-2970.

12. Balthazart J. and Absil P. (1997) Identification of catecholaminergic inputs to and outputs from aromatase-containing brain areas of the Japanese quail by tract tracing combined with tyrosine hydroxylase immunocytochemistry. J. comp. Neurol. 382, 401-428.

13. Balthazart J. and Ball G. F. (1998) The Japanese quail as a model system for the investigation of steroid-catecholamine interactions mediating appetitive and consummatory aspects of male sexual behavior. A. Rev. Sex Res. 9, 96-176.

14. Balthazart J. and Foidart A. (1993) Brain aromatase and the control of male sexual behavior. J. Steroid Biochem. molec. Biol. 44, 521-540.

15. Balthazart J. and Schumacher M. (1984) Estradiol contributes to the postnatal demasculinization of female Japanese quail (Coturnix coturnix japonica). Horm. Behav. 18, 287-297.

16. Balthazart J. and Surlemont C. (1990) Copulatory behavior is controlled by the sexually dimorphic nucleus of the quail POA. Brain Res. Bull. 25, 7-14.

17. Balthazart J., Absil P., Gérard M., Appeltants D. and Ball G. F. (1998) Appetitive and consummatory male sexual behavior in Japanese quail are differentially regulated by subregions of the preoptic medial nucleus. J. Neurosci. 18, 6512-6527.

18. Balthazart J., Castagna C. and Ball G. F. (1997) Aromatase inhibition blocks the activation and sexual differentiation of appetitive male sexual behavior in Japanese quail. Behav. Neurosci. 111, 381-397.

19. Balthazart J., Dupiereux V., Aste N., Viglietti-Panzica C., Barrese M. and Panzica G. C. (1994) Afferent and efferent connections of the sexually dimorphic medial preoptic nucleus of the male quail revealed by in vitro transport of DiI. Cell Tiss. Res. 276, 455-475.

20. Balthazart J., Foidart A., Houbart M., Prins G. S. and Ball G. F. (1998) Distribution of androgen receptor-immunoreactive cells in the quail forebrain and their relationship with aromatase immunoreactivity. J. Neurobiol. 35, 323-340.

21. Balthazart J., Gahr M. and Surlemont C. (1989) Distribution of estrogen receptors in the brain of the Japanese quail: an immunocytochemical study. Brain Res. 501, 205-214.

22. Balthazart J., Reid J., Absil P., Foidart A. and Ball G. F. (1995) Appetitive as well as consummatory aspects of male sexual behavior in quail are activated by androgens and estrogens. Behav. Neurosci. 109, 485-501.

23. Balthazart J., Surlemont C. and Harada N. (1992) Aromatase as a cellular marker of testosterone action in the preoptic area. Physiol. Behav. 51, 395-409.

24. Barbas H., Henion T. H. and Dermon C. R. (1991) Diverse thalamic projections to the prefrontal cortex in the rhesus monkey. J. comp. Neurol. 313, 65-94.

25. Baum M. J. and Everitt B. J. (1992) Increased expression of c-fos in the medial preoptic area after mating in male rats: role of afferent inputs from the medial amygdala and midbrain central tegmental field. Neuroscience 50, 627-646.

26. Baylé J. D., Ramade F. and Oliver J. (1974) Stereotaxic topography of the brain of the quail. J. Physiol., Paris 68, $219-241$.

27. Beach F. A. (1956) Characteristics of masculine "sex drive". Nebraska Symposium on Motivation 4, 1-32.

28. Bock J., Schnabel R. and Braun K. (1997) Role of the dorso-caudal neostriatum in filial imprinting of the domestic chick: a pharmacological and autoradiographic approach focussed on the involvement of NMDA-receptors. Eur. J. Neurosci. 9, 1262-1272.

29. Bradford C. M. and McCabe B. J. (1994) Neuronal activity related to memory in the intermediate and medial part of the hyperstriatum ventrale of the chick brain. Brain Res. 640, 11-16.

30. Brotchie P., Iansek R. and Horne M. K. (1991) Motor function of the monkey globus pallidus neuronal discharge and parameters of movement. Brain 114, $1667-1683$

31. Brown M. W. and Horn G. (1994) Learning-related alterations in the visual responsiveness of neurons in a memory system of the chick brain. Eur. $J$. Neurosci. 6, 1479-1490.

32. Canonaco M., Tavolaro R., Cerra M. C. and Franzoni M. F. (1992) Distribution of benzodiazepine binding sites in the brain of the male Japanese quail and its correlation to a hormonal control: quantitative autoradiography study. Neuroendocrinology 55, 35-43.

33. Canonaco M., Tavolaro R., Cerra M. C., Anastasio M. and Franzoni M. F. (1991) Gonadal regulation of GABA $\mathrm{A}_{\mathrm{A}}$ receptors in the different brain areas of the male Japanese quail. Expl Brain Res. 87, 634-640.

34. Clayton N. S. and Krebs J. R. (1995) Memory in food-storing birds: from behaviour to brain. Curr. Opin Neurobiol. 5, 149-154

35. Cohen D. H. and Karten H. J. (1974) The structural organization of avian brain: an overview. Birds. In Brain and Behavior (eds Goodman I. J. and Schein M. W.), pp. 29-73. Academic, New York.

36. Coolen L. M., Peters H. J. P. W. and Veening J. G. (1996) Fos immunoreactivity in the rat brain following consummatory elements of sexual behavior: a sex comparison. Brain Res. 738, 67-82.

37. Crane P. D., Braun L. D., Cornford E. M., Cremer J. E., Glass J. M. and Oldendorf W. H. (1978) Dose dependent reduction of glucose utilization by pentobarbital in rat brain. Stroke $\mathbf{9 ,} 12-18$ 
38. Delville Y., Hendrick J. C., Sulon J. and Balthazart J. (1984) Testosterone metabolism and testosterone-dependent characteristics in Japanese quail. Physiol. Behav. 33, 817-823.

39. Delville Y., Sulon J. and Balthazart J. (1985) Hormonal correlates of gonadal regression and spontaneous recovery in Japanese quail exposed to short day-lengths. Archs int. Physiol. Biochim. 93, 123-133.

40. Dermon C. R. and Barbas H. (1994) Contralateral thalamic projections predominantly reach transitional cortices in the rhesus monkey. J. comp. Neurol. 344, 508-531.

41. Dermon C. R., Pizarro P., Georgopoulos P. and Savaki H. (1990) Bilateral alterations in local cerebral glucose utilization following intranigral application of the GABAergic agonist muscimol. J. Neurosci. 10, 2861-2878.

42. Dermon C. R., Tzagournissakis M. and Savaki H. E. (1992) Bilateral cerebral metabolic effects of pharmacological manipulation of the substantia nigra in the rat: unilateral intranigral application of the putative excitatory neurotransmitter substance P. Neuroscience 50, 795-809.

43. Divac I. and Mogensen J. (1985) The prefrontal "cortex" in the pigeon-catecholamine histofluoresence. Neuroscience 15, 677-682.

44. Domenici L., Waldvogel H. J., Matute C. and Streit P. (1988) Distribution of GABA-like immunoreactivity in the pigeon brain. Neuroscience 25, 931-950.

45. Domjan M. (1987) Photoperiodic and endocrine control of social proximity behavior in male Japanese quail (Coturnix coturnix japonica). Behav. Neurosci. 101, 385-392.

46. Domjan M. and Hall S. (1986) Determinants of social proximity in Japanese quail (Coturnix coturnix japonica): male behavior. J. comp. Psychol. 100, 59-67.

47. Domjan M., Lyons R., Camille North N. and Bruell J. (1986) Sexual pavlovian conditioned approach behavior in male Japanese quail (Coturnix coturnix japonica). J. comp. Psychol. 100, 413-421.

48. Domjan M. J. (1994) Formulation of a behavior system for sexual conditioning. Psychonom. Bull. Rev. 1, 421-428.

49. Erichsen J. T., Bingman V. P. and Krebs J. R. (1991) The distribution of neuropeptides in the dorsomedial telencephalon of the pigeon (Columba livia): a basis for regional subdivisions. J. comp. Neurol. 314, 478-492.

50. Erichsen J. T., Ciocchetti A., Fontanesi G. and Bagnoli P. (1994) Neuroactive substances in the developing dorsomedial telencephalon of the pigeon (Columba livia): differential distribution and time course of maturation. J. comp. Neurol. 345, 537-561.

51. Fiber J. M., Adames P. and Swann J. M. (1993) Pheromones induce c-fos in limbic areas regulating male hamster mating behavior. NeuroReport 4, $871-874$.

52. Frost B. J., Wylie D. R. and Wang Y.-C. (1990) The processing of object and self motion in the tectofugal and accessory optic pathways of birds. Vision Res. 30, 1677-1688.

53. Funke K. (1989) Somatosensory areas in the telencephalon of the pigeon II. Spinal pathways and afferent connections. Expl Brain Res. 76, 620-638.

54. Georgopoulos A. P., Delong M. R. and Crutcher M. D. (1983) Relations between parameters of step-tracking movements and single cell discharge in the globus pallidus and subthalamic nucleus of the behaving monkey. J. Neurosci. 3, 1586-1598.

55. Hallanger A. E. and Wainer B. H. (1988) Ascending projections from the pedunculopontine tegmental nucleus and the adjacent mesopontine tegmentum in the rat. J. comp. Neurol. 274, 483-515.

56. Hutchison R. E. (1978) Hormonal differentiation of sexual behavior in Japanese quail. Horm. Behav. 11, 363-387.

57. Kadecaro M., Crane A. M. and Sokoloff L. (1985) Differential effects of electrical stimulation of sciatic nerve on metabolic activity in spinal cord and dorsal root ganglion in the rat. Proc. natn. Acad. Sci. U.S.A. 82, 6010-6013.

58. Karten H. J. and Dubbeldam J. L. (1987) The organization and projections of the paleostriatal complex in the pigeon (Columbia livia). J. comp. Neurol. 148, 61-90.

59. Katren H. J. (1968) The ascending auditory pathway in the pigeon (Columba livia) II. Telencephalic projections of the nucleus ovoidalis thalami. Brain Res. 11, 134-153.

60. Kitt C. A. and Brauth S. E. (1981) Projections of the paleostriatum upon the midbrain tegmentum in the pigeon. Neuroscience 6, 1551-1566.

61. Korzeniewska E. and Güntürkün O. (1990) Sensory properties and afferents of the n. dorsolateralis posterior thalami of the pigeon. J. comp. Neurol. 292, $457-479$.

62. Kossut M. and Rose S. P. R. (1984) Differential 2-deoxyglucose uptake into chick brain structures during passive avoidance training. Neuroscience 12, 971-977.

63. Krebs J. R., Erichsen J. T. and Bingman V. P. (1991) The distribution of neurotransmitters and neurotransmitter-related enzymes in the dorsomedial telencephalon of the pigeon (Columba livia). J. comp. Neurol. 314, 467-477.

64. Kuenzel W. J. and Masson M. (1988) A Stereotaxic Atlas of the Brain of the Chick (Gallus domesticus), The Johns Hopkins University Press, Baltimore.

65. Marsden C. D. and Obeso J. A. (1994) The functions of the basal ganglia and the paradox of stereotaxic surgery in Parkinson's disease. Brain 117, $877-897$.

66. Meddle S. L., King V. M., Follett B. K., Wingfield J. C., Ramenofsky M., Foidart A. and Balthazart J. (1997) Copulation activates Fos-like immunoreactivity in the male quail forebrain. Behav. Brain Res. 85, 143-159.

67. Meisel R. L. and Sachs B. D. (1994) The physiology of male sexual behavior. In The Physiology of Reproduction, (eds Knobil E. and Neill J.), Vol. 2 , pp. 3-106. Raven, New York.

68. Metzger M., Jiang S. and Braun K. (1998) Organization of the dorsocaudal neostriatal complex: a retrograde and anterograde tracing study in the domestic chick with special emphasis on the pathways relevant to imprinting. J. comp. Neurol. 395, 380-404.

69. Mink J. W. and Thach W. T. (1991) Basal ganglia motor control. II. Late pallidal timing relative to movement onset and inconsistent pallidal coding of movement parameters. J. Neurophysiol. 65, 301-329.

70. Mogensen J. and Divac I. (1982) The prefrontal "cortrex" in the pigeon. Brain Behav. Evol. 21, 60-66.

71. Panzica G. C., Viglietti-Panzica C., Sanchez F., Sante P. and Balthazart J. (1991) Effects of testosterone on a selected neuronal population within the preoptic sexually dimorphic nucleus of the Japanese quail. J. comp. Neurol. 303, 443-456.

72. Panzica G. C., Viglietti-Panzica C. and Balthazart J. (1996) The sexually dimorphic medial preoptic nucleus of quail: a key brain area mediating steroid action on male sexual behavior. Front. Neuroendocr. 17, 51-125.

73. Patel S. N., Clayton N. S. and Krebs J. R. (1997) Hippocampal tissue transplants reverse lesion-induced spatial memory deficits in zebra finches (Taeniopygia guttata). J. Neurosci. 17, 3861-3869.

74. Pfaus J. G. and Heeb M. M. (1997) Implications of immediate-early gene induction in the brain following sexual stimulation of female and male rodents. Brain Res. Bull. 44, 397-407.

75. Sachs B. D. (1967) Photoperiodic control of the cloacal gland of the Japanese quail. Science 157, 201-203.

76. Sachs B. D. (1969) Photoperiodic control of reproductive behavior and physiology of the male Japanese quail (Coturnix coturnix japonica). Horm. Behav. 1, 7-24

77. Seller T. J. (1981) Midbrain vocalization centers in birds. Trends Neurosci. 4, 301-303.

78. Seller T. J. (1983) Control of sound production in birds. In Bioacoustics: A Comparative Approach (ed. Lewis B.), pp. 93-124. Academic, New York.

79. Sokoloff L., Reivich M., Kennedy C., Des Rosiers M. H., Patlak C. S., Pettigrew D. K., Sakurada O. and Shinohara M. (1977) The [ ${ }^{14}$ C]deoxyglucose method for the measurement of local cerebral glucose utilization: theory, procedure and normal values in the conscious and anesthetized albinos rat. J. Neurochem. 28, 897-916.

80. Stewart M. G. (1991) Changes in dendritic structure in chick forebrain consequent on passive avoidance learning. In Neural and Behavioural Plasticity: The Use of Domestic Chick as a Model. (ed. Andrew R. J.), pp. 305-328. Oxford University Press, Oxford.

81. Szekely A. D., Boxer M. I., Stewart M. G. and Csillag A. (1994) Connectivity of the lobus parolfactorious of the domestic chicken (Gallus domesticus): an anterograde and retrograde pathway tracing study. J. comp. Neurol. 348, 374-393. 
82. Teruyama R. and Beck M. M. (1995) Development of metabolic response in male quail brain during sexual maturation. Brain Res. 697, $169-178$.

83. Thompson R. R. and Adkins-Regan E. (1994) Photoperiod affects the morphology of a sexually dimorphic nucleus within the preoptic area of male Japanese quail. Brain Res. 667, 201-208.

84. Veeman C. L. and Reiner A. (1994) The distribution of GABA-containing perikarya, fibers, and terminals in the forebrain and midbrain of pigeons, with particular reference to the basal ganglia and its projection targets. J. comp. Neurol. 339, 209-250.

85. Veening J. G. and Coolen L. M. (1998) Neural activation following sexual behavior in the male and female rat brain. Behav. Brain Res. 92, 181-193.

86. Villani L., Dipietrangelo L., Pallotti C., Pettazzoni P., Zironi I. and Guarnieri T. (1994) Ultrastructural and immunohistochemical study of the telencephalo-habenulo-interpenduncular connections of the goldfish. Brain Res. Bull. 34, 1-5.

87. Waldmann C. and Güntürkün O. (1993) The dopaminergic innervation of the pigeon caudolateral forebrain: immunocytochemical evidence for a "prefrontal cortex" in birds? Brain Res. 600, 225-234.

88. Watson J. T. and Adkins-Regan E. (1989) Neuroanatomical localization of sex steroid-concentrating cells in the Japanese quail (Coturnix japonica): autoradiography with $\left[{ }^{3} \mathrm{H}\right]$-testosterone, $\left[{ }^{3} \mathrm{H}\right]$-estradiol, and $\left[{ }^{3} \mathrm{H}\right]$-dihydrotestosterone. Neuroendocrinology 49, 51-64.

89. Watson J. T. and Adkins-Regan E. (1989) Activation of sexual behavior by implantation of testosterone propionate and estradiol benzoate into the preoptic area of the male Japanese quail (Coturnix japonica). Horm. Behav. 23, 251-268.

90. Wersinger S. R., Baum M. J. and Erskine M. S. (1993) Mating-induced FOS-like immunoreactivity in the rat forebrain: a sex comparison and a dimorphic effect of pelvic nerve transection. J. Neuroendocr. 5, 557-568.

91. Wild J. M. (1987) Nuclei of lateral lemniscus project directly to the thalamic auditory nuclei in the pigeon. Brain Res. 408, 303-307.

92. Wild J. M., Karten H. J. and Frost B. J. (1993) Connections of the auditory forebrain in the pigeon. J. comp. Neurol. 337, 32-62.

93. Wood R. I. and Coolen L. M. (1997) Integration of chemosensory and hormonal cues is essential for sexual behaviour in the male Syrian hamster: role of the medial amygdaloid nucleus. Neuroscience 78, 1027-1035.

94. Wynne B. and Güntürkün O. (1995) Dopaminergic innervation of the telencephalon of the pigeon (Columbia livia): a study with antibodies against tyrosine hydroxylase and dopamine. J. comp. Neurol. 357, 446-464.

95. Wyss J. M., Swanson L. W. and Cowan W. M. (1979) A study of subcortical afferents to the hippocampal formation in the rat. Neuroscience 4, 463-476.

96. Yasaki Y., Matsushima T. and Aoki K. (1995) The role of the mesencephalic call region in the Japanese quail chick. In Nervous Systems and Behaviour. Proceedings of the 4th International Congress of Neuroethology (eds Burrows M., Matheson T., Newland P. L. and Schuppe H.), pp. 319. Georg Thieme Verlag, Stuttgart, New York. 